Hydrol. Earth Syst. Sci., 17, 2929-2946, 2013

www.hydrol-earth-syst-sci.net/17/2929/2013/

doi:10.5194/hess-17-2929-2013

(c) Author(s) 2013. CC Attribution 3.0 License.

\title{
Assimilating in situ and radar altimetry data into a large-scale hydrologic-hydrodynamic model for streamflow forecast in the
}

\section{Amazon}

\author{
R. C. D. Paiva ${ }^{1,2}$, W. Collischonn ${ }^{1}$, M.-P. Bonnet ${ }^{2}$, L. G. G. de Gonçalves ${ }^{3}$, S. Calmant ${ }^{4}$, A. Getirana ${ }^{5}$, and J. Santos da \\ Silva ${ }^{6}$ \\ ${ }^{1}$ Instituto de Pesquisas Hidráulicas IPH, Universidade Federal do Rio Grande do Sul UFRGS, Brazil \\ ${ }^{2}$ Géosciences Environnement Toulouse GET, UMR5563, CNRS IRD UPS - OMP, Université Toulouse III Paul Sabatier, \\ Toulouse, France \\ ${ }^{3}$ CPTEC/INPE - Centro de Previsão de Tempo e Estudos Climáticos, Instituto Nacional de Pesquisas Espaciais, \\ Cachoeira Paulista, Brazil \\ ${ }^{4}$ Laboratoire d'Etudes en Géophysique et Océanographie Spatiales LEGOS (UMR 5566 CNES CNRS IRD UPS), OMP, \\ Université Toulouse III Paul Sabatier, Toulouse, France \\ ${ }^{5}$ NASA Goddard Space Flight Center, Hydrological Sciences Lab,Greenbelt, USA \\ ${ }^{6}$ Universidade do Estado do Amazonas UEA, Brazil
}

Correspondence to: R. C. D. Paiva (rodrigocdpaiva@gmail.com)

Received: 1 February 2013 - Published in Hydrol. Earth Syst. Sci. Discuss.: 7 March 2013

Revised: 30 May 2013 - Accepted: 17 June 2013 - Published: 24 July 2013

\begin{abstract}
In this work, we introduce and evaluate a data assimilation framework for gauged and radar altimetrybased discharge and water levels applied to a large scale hydrologic-hydrodynamic model for stream flow forecasts over the Amazon River basin. We used the process-based hydrological model called MGB-IPH coupled with a river hydrodynamic module using a storage model for floodplains. The Ensemble Kalman Filter technique was used to assimilate information from hundreds of gauging and altimetry stations based on ENVISAT satellite data. Model state variables errors were generated by corrupting precipitation forcing, considering log-normally distributed, time and spatially correlated errors. The EnKF performed well when assimilating in situ discharge, by improving model estimates at the assimilation sites (change in root-meansquared error $\Delta \mathrm{rms}=-49 \%)$ and also transferring information to ungauged rivers reaches $(\Delta \mathrm{rms}=-16 \%)$. Altimetry data assimilation improves results, in terms of water levels $(\Delta \mathrm{rms}=-44 \%)$ and discharges $(\Delta \mathrm{rms}=-15 \%)$ to a minor degree, mostly close to altimetry sites and at a daily basis, even though radar altimetry data has a low temporal resolution. Sensitivity tests highlighted the importance of the
\end{abstract}

magnitude of the precipitation errors and that of their spatial correlation, while temporal correlation showed to be dispensable. The deterioration of model performance at some unmonitored reaches indicates the need for proper characterisation of model errors and spatial localisation techniques for hydrological applications. Finally, we evaluated stream flow forecasts for the Amazon basin based on initial conditions produced by the data assimilation scheme and using the ensemble stream flow prediction approach where the model is forced by past meteorological forcings. The resulting forecasts agreed well with the observations and maintained meaningful skill at large rivers even for long lead times, e.g. $>90$ days at the Solimões/Amazon main stem. Results encourage the potential of hydrological forecasts at large rivers and/or poorly monitored regions by combining models and remote-sensing information. 


\section{Introduction}

Land surface waters play an important role in global water cycle and earth system, regulating freshwater discharge from land into oceans (Oki and Kanae, 2006) and also land-atmosphere exchanges of water, energy (Krinner, 2003; Decharme et al., 2011) and gases such as methane (Gedney et al., 2004). Moreover, it directly affects society that uses it for drinking water and also transportation of people and goods, agriculture and energy production from hydropower. More specific to the Amazon basin, important extreme hydrological events have occurred recently, for instance, the 2009 and 2012 floods and the 1996, 2005 and 2010 droughts (Chen et al., 2010; Tomasella et al., 2010; Marengo et al., 2008, 2011; Espinoza et al., 2011). These events caused several impacts on local population that strongly depends on the rivers and is very vulnerable to floods since most settlements lie along the rivers.

In situ measurements of river stage and discharge at stream gauges are the most conventional alternative for monitoring surface waters, although observation networks are rather sparse at several regions such as the Amazon River basin. Alternatively, radar altimetry techniques have been developed in past years to monitor water levels (e.g. Santos da Silva et al., 2010; Alsdorf et al., 2007) or discharges using rating curves (e.g. Leon et al., 2006; Papa et al., 2010a; Getirana and Peters-Lidard, 2013). If compared to in situ gauges in remote regions, these satellite instruments can provide observations with much better spatial coverage, but with worse temporal sampling. Moreover, the forthcoming Surface Water and Ocean Topography (SWOT) mission (Durand et al., 2010a) is designed to provide high resolution images of inland water surface elevation, including rivers, lakes, wetlands and reservoirs, using a swath mapping radar altimeter with high frequency repeat orbit. Additionally, it may also be possible to derive discharge estimates from SWOT data by using specially developed algorithms (e.g. Durand et al., 2010b).

In contrast, there are several efforts on hydrological modelling to simulate processes as river and floodplain dynamics in large river basins such as the Amazon (Paiva et al., 2013a, b; Yamazaki et al., 2011; Getirana et al., 2012; Decharme et al., 2011; Coe et al., 2008; Wilson et al., 2007; Trigg et al., 2009). These models can potentially provide detailed information on surface waters, both spatially and temporally, but such estimates are somehow imperfect due to uncertainty in model structure, parameters and forcing data (Liu and Gupta, 2007).

Data assimilation (DA) methods are an alternative to optimally merge uncertain model predictions with both in situ and the newly remote-sensing observations of surface waters. The aim of DA techniques is to "produce physically consistent representations or estimates of the dynamical behaviour of a system by merging the information present in imperfect models and uncertain data in an optimal way to achieve uncertainty quantification and reduction" (Liu and Gupta,
2007). Such methods can also be used to estimate balanced initial states of hydrological models for forecasting the aforementioned extreme events. There are already some hydrological regional/global forecast systems founded on physicallybased hydrological models (e.g. Wood et al., 2002; Thielen et al., 2009; Alfieri et al., 2013), and also several physical modelling experiments in the Amazon basin, as previously mentioned. However, current attempts for developing hydrological forecasts in this particular basin are mostly based on statistical methods (e.g. Uvo and Grahan, 1998; Uvo et al., 2000). Furthermore, Paiva et al. (2012) showed that, for lead times up to 3 months, uncertainty of initial conditions plays a major role for discharge predictability on main Amazonian Rivers, if compared to the importance of precipitation forcing, suggesting the importance of DA techniques for streamflow forecasts in this region.

Research on data assimilation applied to hydrology has increased in past years with various applications utilising Kalman filters (e.g. the Ensemble Kalman Filter - EnKF, developed by Evensen, 2003), particle filters or variational methods, as extensively reviewed in Liu and Gupta (2007), Reichle (2008) and Liu et al. (2012). These applications include a wide range of observations, both in situ and remotely sensed, data assimilation methods and models representing different hydrological processes, at different spatial scales and with several objectives, such as: the assimilation of snow (Andreadis and Lettenmaier, 2006) and soil moisture (Reichle et al., 2002) data into land surface models using the EnKF; assimilation of in situ water level measurements into a small scale 1-D hydrodynamic model for flood forecast using Kalman filtering methods (Neal et al., 2007; Ricci et al., 2011); assimilation of synthetic SWOT data into hydrodynamic models at restricted areas using the EnKF and some variations (Biancamaria et al., 2011; Andreadis et al., 2007; Durand et al., 2008); assimilation of discharge data into distributed hydrological models (Clark et al., 2008; McMillan et al., 2013; Lee et al., 2012; Thirel et al., 2010; Rakovec et al., 2012) using the EnKF or variational methods; simultaneous assimilation of soil moisture and discharge data into a distributed hydrological model using variational DA (Lee et al., 2011); assimilation of radar altimetry data of reservoir water levels using the EnKF (Pereira-Cardenal et al., 2011); development of a modelling platform (Land Information System LIS) to merge multiple in situ and remotely sensed observations with land surface models (Kumar et al., 2008); merging water levels information derived from a satellite Synthetic Aperture Radar (SAR) image and digital terrain model (DTM) with a 1-D hydrodynamic model for estimating river discharge (Neal et al., 2009); assimilation of water levels derived from SAR images and DTMs into hydrodynamic models using variational (Hostache et al., 2010) or particle filter (Matgen et al., 2010; Giustarini et al., 2011) methods; assimilating water levels and surface velocity derived from floaters monitored by global navigation satellite systems into hydrodynamic models (Hostache et al., 2011); among others. 
Although there is an extensive bibliography on hydrological data assimilation, the current state of the art regional/global hydrological prediction systems (e.g. Thielen et al., 2009; Alfieri et al., 2013) still do not incorporate advanced data assimilation systems for updating model initial states. Also, the assimilation of discharge and water levels from in situ and remotely sensed observations into regional/global hydrologichydrodynamic models is still uncommon.

In this paper, we present the development and evaluation of a data assimilation framework for both gauged and radar altimetry-based discharge and water levels into a large scale hydrologic-hydrodynamic model of the Amazon River basin using the EnKF. We also explore the usefulness of such system to provide streamflow forecasts when forced by past remotely sensed precipitation data and based mostly on model initial conditions. This paper is in the context of recent developments of techniques for integrating information from hydrological models with newly remotely sensed data such as the forthcoming SWOT mission and also in the context of regional/global hydrological forecast systems including large, poorly gauged river basins. Through our experimental results, we explore questions such as: is an EnKF-based DA scheme feasible for assimilating discharge and water level data into large scale hydrologic-hydrodynamic models? Is it able to improve discharge and water level estimates at sites where data were assimilated and also at ungauged rivers? Does the assimilation of radar altimetry data also improve model estimates at large river basins, considering that it has lower temporal resolution and accuracy if compared to gauged in situ data? Would it be possible to provide accurate streamflow forecasts at large basins such as the Amazon using a large scale hydrologic-hydrodynamic model based mostly on the initial hydrological states gathered by the DA scheme? At which spatial and temporal scales?

\section{Methods}

\subsection{The hydrologic-hydrodynamic model}

We used the MGB-IPH model (Collischonn et al., 2007), which is a large scale, distributed and process-based hydrological model with a hydrodynamic module described in Paiva et al. (2011). It simulates surface energy and water balance and also discharge, water level and flood inundation on a complex river network. Vertical hydrological processes include soil water budget using a bucket model, energy budget and evapotranspiration using the Penman Monteith approach, and also surface, subsurface and groundwater flow generation, among others. The flow generated within each catchment is routed to the stream network using a linear reservoir type model. River flow routing is performed using a combination of either a Muskingum-Cunge (MC) method or a hydrodynamic model (HD).
The hydrodynamic model of MGB-IPH (Paiva et al., 2011) solves the full 1-D Saint-Venant equations for the river network and flood inundation is simulated using a simple model assuming that the floodplains act only as storage areas. Riverfloodplain parameters (river width, bottom levels, roughness coefficient, floodplain bathymetry) are estimated using GISbased algorithms from the Shuttle Radar Topography Mission (SRTM) Digital Elevation Model (DEM) (Farr et al., 2007) and using geomorphological relations.

\subsection{The Ensemble Kalman Filter}

The goal of data assimilation is to combine the uncertain and complementary information from measurements and simulation models into an optimal estimate of the hydrological fields of interest, providing a general framework for dealing with uncertainty from measurements and also from model inputs, structure and outputs (Reichle, 2008; Liu and Gupta, 2007; Liu et al., 2012; Vrugt et al., 2005).

A great part of the hydrological applications of data assimilation methods uses schemes based on the Kalman filter (Kalman, 1960), specially the Ensemble Kalman Filter (Evensen, 2003, 2009), which is also used in this study and is briefly described below. The model representing the dynamics of the simulated system can be shown in a discrete form by the process equation:

$\boldsymbol{x}_{k+1}=M\left(\boldsymbol{x}_{k}, \boldsymbol{u}_{k}, \boldsymbol{\theta}\right)+\boldsymbol{q}_{k}$

where $\boldsymbol{x}$ represents the state variables and, $\boldsymbol{u}$ and $\boldsymbol{\theta}$ represent model forcings and parameters respectively, $M$ is the nonlinear model operator that relates model states from time interval $t_{k}$ to $t_{k+1}=t_{k}+\Delta t$, and $\boldsymbol{q}_{k}$ represents errors in model structure, parameter, forcings and antecedent states. In this study, $\boldsymbol{x}$ is a vector composed by all MGB-IPH state variables, i.e. soil moisture, storage and discharge from surface, subsurface and groundwater reservoirs, soil temperature, canopy storage and river discharge and water level. The measurement equation is defined by:

$\boldsymbol{y}_{k}=H\left(\boldsymbol{x}_{k}\right)+\boldsymbol{\varepsilon}_{k}$

where $\boldsymbol{y}$ is observation vector, $\boldsymbol{\varepsilon}$ is the vector of observation errors and $H$ is the observation operator which relates the model state variables vector $\boldsymbol{x}$ to the observations vector $\boldsymbol{y}$. In our case, observations are river discharges or water levels at selected sites.

In the context of forecast systems and sequential data assimilation methods, at each time interval, the model is integrated in time using Eq. (1) to provide a short-term forecast (or background) $\boldsymbol{x}_{k+1}^{\mathrm{f}}$ and whenever an observation is available, the forecast errors (called model innovations) are computed as $\left(\boldsymbol{y}_{k+1}-H\left(\boldsymbol{x}_{k+1}^{\mathrm{f}}\right)\right)$. Therefore, the goal of data assimilation is to obtain an optimal estimate of model state variables $\boldsymbol{x}^{\mathrm{a}}$ (called analysis) given model and observation errors. In the case of the original Kalman Filter (Kalman, 
$1960)$, the DA problem is solved using a linear estimator assuming that (i) model and observation operators ( $M$ and $H$ ) are linear; (ii) observation errors are unbiased and both temporally and spatially uncorrelated; (iii) model errors are unbiased and temporally uncorrelated; and (iv) there is no correlation between model and observation errors. Consequently, an unbiased and minimum variance estimate of model states is obtained by:

$x^{\mathrm{a}}=\boldsymbol{x}^{\mathrm{f}}+\mathbf{K}\left(\boldsymbol{y}-\mathbf{H} \boldsymbol{x}^{\mathrm{f}}\right)$

$\mathbf{K}=\mathbf{P}^{\mathrm{f}} \mathbf{H}^{T}\left[\mathbf{H} \mathbf{P}^{\mathrm{f}} \mathbf{H}^{T}+\mathbf{R}\right]^{-1}$

where $\mathbf{K}$ is the Kalman gain, $\mathbf{P}$ is the covariance of model errors $\boldsymbol{q}$, and $\mathbf{R}$ is the covariance of measurement errors $\boldsymbol{\varepsilon}$. The Kalman filter also provides the maximum likelihood solution of the DA problem when model and measurement errors are assumed to be also Gaussian. However, the applicability of the KF is limited since most hydrological systems exhibit nonlinear dynamics (Liu and Gupta, 2007) and the assumptions about model errors (e.g. Gaussian, unbiased, among others) are not always valid. Moreover, both the original KF and also its nonlinear version, the Extended KF (EKF), have additional drawbacks when applied in large and complex systems with lots of state variables (e.g. distributed hydrological models) due to extra programming and heavy computational requirements associated with the storage and forward integration of the error covariance matrix $\mathbf{P}$ (Vrugt et al., 2005).

Evensen (2003) presented the Ensemble Kalman Filter (EnKF), which is a stochastic or Monte Carlo alternative for the deterministic EKF (Evensen, 2009). In this method, ensembles of model states and/or observations are generated using a priori-known errors and by means of the model operator $M$, the algorithm generates an ensemble of model trajectories from which the time evolution of model errors and error covariance matrix can be sampled:

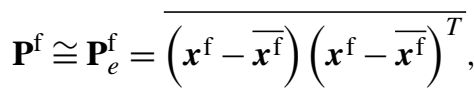

$\mathbf{P}^{\mathrm{a}} \cong \mathbf{P}_{e}^{\mathrm{a}}=\overline{\left(x^{\mathrm{a}}-\overline{\boldsymbol{x}^{\mathrm{a}}}\right)\left(x^{\mathrm{a}}-\overline{x^{\mathrm{a}}}\right)^{T}}$.

Each ensemble member is then updated using the same analysis equation from the original KF (Eqs. 3 and 4). Alternatively, efficient computational implementations of the EnKF are presented in Evensen (2003, 2004 and 2009) (see http: //enkf.nersc.no/ for Fortran codes) where the explicit computation and storage of $\mathbf{P}^{\mathrm{f}}$ are not required. We used the square root scheme presented in Evensen $(2004,2009)$ where the perturbation of measurements is not performed, in order to reduce sampling errors.

For linear systems and with large ensemble sizes, the EnKF provides the same solution as the KF method. However, it is noteworthy that it does not fully take into account non-Gaussian errors nor solve the Bayesian update equation for non-Gaussian probability distribution functions. Still, it is a computational efficient analysis scheme for nonlinear models that provides a satisfactory solution, although it is suboptimal, that somehow lies between a linear Gaussian update and a full Bayesian computation (Evensen, 2009). Also, the advantage of the EnKF is that it can be easily implemented in any mathematical model, e.g. it does not require the development of a particular adjoint model as the variational methods, and it usually requires smaller ensemble sizes, and consequently less computational effort, if compared to particle filter methods (Liu et al., 2012).

\subsection{Uncertainty in precipitation forcing}

We perturbed model states variables by adding a noise in precipitation forcing, considering (i) that this is the most uncertain model input (Liu et al., 2012) and possibly the most important source of model uncertainty and (ii) that this is a proper method to generate physically coherent model errors. A similar approach performed satisfactorily in other hydrological applications of DA methods such as Andreadis and Lettenmaier (2006) and Biancamaria et al. (2011). Precipitation values were corrupted using a log-normally distribution as presented by Nijjsen and Lettenmaier (2004) and also applied by Andreadis and Lettenmaier (2006):

$P_{c}=\frac{1+\beta}{\sqrt{E^{2}+1}} \exp \left(\sqrt{\ln \left[E^{2}+1\right]} s\right) P$

where $P_{c}\left[\mathrm{~mm} \Delta \mathrm{t}^{-1}\right]$ is the perturbed daily precipitation, $P$ $\left[\mathrm{mm} \Delta \mathrm{t}^{-1}\right]$ is the unperturbed daily precipitation, $E$ is the relative error [\%], $\beta$ is the relative bias and $s \sim N(0,1)$ is a normally distributed and spatially correlated random variable with zero mean and unit variance. Spatially correlated pseudo random fields $\boldsymbol{w}$ were generated by means of the algorithm based on the two dimensional Fourier transform presented in Evensen (2003) (see http://enkf.nersc.no/ for Fortran codes), having zero mean, unit variance and isotropic covariance function decreasing to the $e^{-1}$ value at the distance $\tau_{\mathrm{x}}$ called spatial decorrelation length. At each spatial location, temporal correlation was also considered using the following equation for simulating the time evolution of errors (Evensen, 2003):

$s_{k}=\alpha s_{k-1}+\sqrt{1-\alpha^{2}} w_{k-1}$

where $k$ is the time interval, $s_{k}$ is a sequence of time correlated errors with zero mean and unit variance (input for Eq. 6) and $\alpha$ determines the time decorrelation of the stochastic forcing, e.g. $\alpha=0$ generates a sequence of white noise while $\alpha=1$ removes the stochastic forcing. The parameter $\alpha$ is determined by:

$\alpha=1-\frac{\Delta t}{\tau_{\mathrm{t}}}$

where $\tau_{\mathrm{t}}$ is the temporal decorrelation length, that determines that $s$ decreases by the ratio $e^{-1}$ after a time period $t=\tau_{\mathrm{t}}$ if the stochastic term $w$ is excluded. 


\subsection{Measurement errors}

Water level $(z)$ and discharge $(Q)$ observations errors were modelled using the following relations:

$z_{c}=z+\varepsilon_{z}, \varepsilon_{z} \sim N\left(0, \sigma_{z}^{2}\right)$

$Q_{c}=Q+\varepsilon_{Q}, \varepsilon_{Q} \sim N\left(0,\left(\sigma_{Q} Q\right)^{2}\right)$

where $z_{c}[\mathrm{~m}]$ and $Q_{c}\left[\mathrm{~m}^{3} \mathrm{~s}^{-1}\right]$ are the observations of $z[\mathrm{~m}]$ and $Q\left[\mathrm{~m}^{3} \mathrm{~s}^{-1}\right], \varepsilon_{z}[\mathrm{~m}]$ and $\varepsilon_{Q}\left[\mathrm{~m}^{3} \mathrm{~s}^{-1}\right]$ are the normally distributed errors with parameters $\sigma_{z}[\mathrm{~m}]$ and $\sigma_{Q}[\%]$ of $z$ and $Q$, respectively. The formulation of discharge errors allows representing larger uncertainties for high stage levels than for low flows due to uncertainties in discharge rating curves, as pointed out by Clark et al. (2008). Alternatively, simulated and observed discharges were also transformed into the $\log$ space before the assimilation, following Clark et al. (2008). In this case, observation errors were modelled by:

$Q_{c}=\varepsilon^{\prime}{ }_{Q} Q, \varepsilon^{\prime}{ }_{Q} \sim \log N\left(1, \sigma^{\prime 2}{ }_{Q}\right)$

where now $\varepsilon^{\prime} Q$ is a log-normally distributed error with unit mean and standard deviation $\sigma^{\prime} Q$ [\%], similar to Eq. (10). At $\log$ space, standard deviation is given by $\sigma^{\prime} \log Q=$ $\sqrt{\log \left({\sigma^{\prime}}_{Q}^{2}+1\right)}$.

\section{Experimental design}

\subsection{The Amazon River basin}

The study area is the Amazon River basin, known as the largest hydrological system of the world $\left(\sim 6\right.$ million $\mathrm{km}^{2}$ of surface area) and contributing with $\sim 15 \%$ to the total fresh water released into the oceans. The Amazon basin is characterised by extensive seasonally flooded areas (Hess et al., 2003; Papa et al., 2010b; Melack and Hess, 2010), which store and release large amounts of water from the rivers and consequently attenuate and delay flood waves in several days or months (Paiva et al., 2013a, b; Yamazaki et al., 2011). Also, complex river hydraulics are present, where the low river slopes cause backwater effects that control part of river dynamics (Meade, 1991; Trigg et al., 2009; Tomasella et al., 2010; Paiva et al., 2013a, b). Additionally, this region presents high precipitation rates (average $\sim 2200 \mathrm{~mm} \mathrm{yr}^{-1}$ ) with high spatial variability and contrasting rainfall regimes in the northern (rainfall peak at JJA) and southern (rainfall peak at DJF) parts of the basin, with more defined wet and dry seasons occurring in southern and eastern regions (Espinoza et al., 2009).

\subsection{Model implementation}

We used a MGB-IPH implementation on the Amazon basin developed by Paiva et al. (2013b), as briefly described below. The model was forced using meteorological data obtained from the CRU CL 2.0 dataset (New et al., 2002) and remotely sensed precipitation estimates from the TRMM 3 B42 v6 product (Huffman et al., 2007), with spatial resolution of $0.25^{\circ} \times 0.25^{\circ}$ and daily time step for a period spanning $12 \mathrm{yr}$ (1998-2009). The model parameters related to soil water budget were calibrated using daily discharge data from stream gauges (see next section for description of gauged data). Then, the model was validated against daily discharge and water level data from stream gauge stations, water levels derived from ENVISAT satellite altimetry data (Santos da Silva et al., 2010) (212 sites with 35-day repeat orbit), monthly Terrestrial Water Storage from GRACE mission (Frappart et al., 2010, 2011) and monthly flood inundation extent from Papa et al. (2010b). Simulations agreed with observations, with relatively high Nash and Suttcliffe index $\left(E_{\mathrm{NS}}\right)$ values: $E_{\mathrm{NS}}>0.6$ in $\sim 70 \%$ of discharge gauges, $E_{\mathrm{NS}}>0.6$ in $\sim 60 \%$ of the water level stations derived from satellite altimetry, $E_{\mathrm{NS}}=0.71$ for total flood extent and $E_{\mathrm{NS}}=0.93$ for terrestrial water storage.

Since this study aimed at applications of data assimilation to hydrological forecasting, we also used a real time precipitation product to force the MGB-IPH model. We choose to use the TRMM Merge product (Rozante et al., 2010), which is a near to real time precipitation estimate based on TRMM 3B42RT (Huffman et al., 2007) merged with data from in situ gauges and provided by the Brazilian centre for weather forecasts and climate studies CPTEC (Centro de Previsão do Tempo e Estudos Climáticos), a division of the Brazilian National Institute for Space Research INPE (Instituto Nacional de Pesquisas Espaciais).

\subsection{Discharge and water level observations}

We evaluated the assimilation of three types of data: (1) in situ discharge observations; (2) remotely sensed water levels derived from the ENVISAT radar altimeter; and (3) remotely sensed discharge estimates derived from radar altimetry water levels and rating curves.

In situ daily discharge from 109 stream gauges were provided by the Brazilian agency for water resources ANA (Agência Nacional das Águas), the Peruvian and Bolivian national meteorology and hydrology services SENAMHI (Servicio Nacional de Meteorología e Hidrología) and the French ORE-HYBAM programme (Hydrologie, Biogeochimie and Geodynamique du Bassin Amazonien, http: //www.ore-hybam.org). We also used stage data from 66 ANA gauge stations, but only for validation purposes.

Remotely sensed water levels were obtained from the ENVISAT satellite altimeter. The ENVISAT satellite has a 35day repeat orbit and an $80 \mathrm{~km}$ inter-track distance at the 
Equator. The database used is an extension of the one presented in Santos da Silva et al. (2010), consisting in 212 altimetry stations (AS - deduced from the intersection of a satellite track with a water body) with water level time series for the 2002-2009 period. ENVISAT data selection techniques preconized by Santos da Silva et al. (2010) result in $\sim 10$ to $40 \mathrm{~cm}$ water level accuracy. Due to differences in water levels datum reference, the comparisons between simulated and observed water levels were performed in terms of anomalies, i.e. after removing the long-term average.

Altimetry-based discharge data was developed by Getirana and Peters-Lidard (2013) for the Amazon basin. This dataset was constructed using a rating-curve-based methodology deriving water discharge from ENVISAT altimetry data at 475 altimetric stations. The stage-discharge relations at each AS were built based on satellite altimetry and outputs from a global flow routing (GFR) scheme (Getirana et al., 2012). A second experiment was performed by Getirana and PetersLidard (2013) using observed discharges at gauge stations to force the GFR scheme at downstream reaches. Validation of the methodology against observed discharges at 90 sites showed a mean relative error of $27 \%$ for the experiment using in situ discharge within the GFR scheme. We assimilated data only from the 287 ASs located downstream of a gauging station where the accuracy of discharge estimates from Getirana and Peters-Lidard (2013) was generally better.

\subsection{Parameters of the DA scheme}

The first sensitivity experiments used the following standard parameters of the DA scheme. Ensemble size of the EnKF was set as $N=200$. Precipitation fields were corrupted considering the following error parameters: precipitation relative error $E=25 \%$, and precipitation relative bias $\beta=1.0$ following Andreadis and Lettenmaier (2006); temporal decorrelation length of precipitation errors $\tau_{\mathrm{t}}=10$ days; and spatial decorrelation length of precipitation errors $\tau_{\mathrm{x}}=1.0^{\circ}$, similarly to Andreadis and Lettenmaier (2006) and Clark et al. (2008). The parameter of water level measurements error was set as $\sigma_{z}=0.20 \mathrm{~m}$, based on the accuracy of ENVISAT estimates provided by Santos da Silva et al. (2010). We computed the mean relative error between in situ discharge measurements and values provided by rating curves at 87 gauging stations from the ANA database as a surrogate of the discharge error parameter $\sigma_{Q}$. The median value of all stations was $13 \%$, while Clark et al. (2008) used $10 \%$ in its DA experiments. Therefore, we choose to also use $\sigma_{Q}=10 \%$ for simplicity. We used $\sigma_{Q}=27 \%$ for assimilation of satellite based discharge data, based on the error value found in Getirana and Peters-Lidard (2013).

\subsection{Data assimilation experiments}

We performed three data assimilation experiments, namely: (i) in situ discharge assimilation (Exp 1) (ii) Radar altimetry assimilation (Exp 2) and (iii) Assimilation of discharge series based on satellite altimetry $(\operatorname{Exp} 3)$.

In the first experiment, we tested: (Exp. 1a) the assimilation of discharge from almost all gauge stations $(80 \%)$ using a few of them for validation $(20 \%)$, where these stations where randomly chosen; (Exp. 1b) the assimilation of only 12 stations $(\sim 10 \%)$ located at some of the major tributaries to emulate the situation of using only telemetric stream gauges for real time applications - we choose 1 or 2 stations located at the downstream reach of the largest Amazonian rivers; (Exp. 1c) the assimilation of discharge from almost all gauge stations, similar to (Exp. 1a), but without transforming discharge into the log space (Sect. 2.4.). Moreover, we explored the sensitivity of the DA scheme to some of its parameters, namely the ensemble size $N$, precipitation relative error $E$ and temporal and spatial decorrelation lengths of precipitation errors $\tau_{\mathrm{t}}$, and $\tau_{\mathrm{x}}$.

The second experiment (Exp. 2) evaluated the assimilation of ENVISAT radar altimetry water level anomalies from all altimetry stations. Stage data from all in situ gauges were used for model verification. Simulations were also compared in terms of discharge using in situ data to evaluate the impact of water level assimilation in discharge estimates.

In the third experiment (Exp. 3), we assessed the assimilation of discharge derived from radar altimetry water level at all altimetry stations. Discharge data from all stream gauges were used for verification.

In all cases, simulations started in 1998 and ran to 2002 for model spin-up. The year of 2003 was used for the spin-up of the DA scheme, where no update was performed in the first months allowing the system to develop a coherent correlation structure, following Andreadis and Lettenmaier (2006). To access the DA scheme performance, model simulations using (EnKF simulation) and not using (Open-loop simulation) data assimilation were compared. Results were evaluated for the two year period 2004-2005 by means of the following model performance statistics that compare simulation results with observations: (i) the Nash-Suttcliffe coefficient $E_{\mathrm{NS}}$ ranging from $-\infty$ to 1 (optimum) and (ii) changes in rootmean-square error $\Delta \mathrm{rms}=100\left(\mathrm{rms}_{2}-\mathrm{rms}_{1}\right) / \mathrm{rms}_{1}$, ranging from $-100 \%$ (optimum) to $\infty$, where $\mathrm{rms}_{1}$ and $\mathrm{rms}_{2}$ are root-mean-squared errors from Open-loop and EnKF simulations, respectively. The period 2004-2005 was chosen for its highest availability of in situ discharge and stage data together with altimetry data, and also because it contains an important extreme hydrological event - the 2005 drought.

\subsection{Prospects of streamflow forecasting}

Hindcast streamflow forecasts were generated using an ensemble streamflow prediction (ESP) approach (Day, 1985), as described below. The model uses an estimate of initial conditions derived from the DA scheme and runs forced by an ensemble of observed meteorological data from past years. An estimate of initial conditions is computed during 
the spin-up period using a hydrological model driven by observed meteorological forcings, updated using data assimilation of observations up to the time of forecast (e.g. forecast starts with model states from 1 June of 2010). Then, an ensemble forecast is obtained using observed meteorological data resampled from past years (e.g. meteorological data from 1 June to 1 September of years 1998, 1999,.., 2009).

Precipitation from TRMM Merge was used during spinup period, while during forecast the model was forced with TRMM 3B42 data for the period spanning 12 years (19982009) and, consequently, the forecast ensemble had 12 members. The DA scheme used the configuration from Exp. 1b where in situ discharge data were assimilated to update model states before starting a forecast. ESP runs generated decadal forecasts up to 90 days lead time and starting at every 1 st, 10th and 20th day of the month for the two year period of 2004-2005. Aiming at exploring the usefulness of such system to provide streamflow forecasts in future applications, we chose to test it for a past period (2004-2005) where a large amount of discharge data is available for verification. For simplicity reasons, forecasts were evaluated only by deterministic means by averaging ensemble values into a single forecast. We used the skill score $\mathrm{SS}_{\text {cli }}$ which compares the performance of the model forecasts with a control forecast based on climatology (Wilks, 2006):

$\mathrm{SS}_{\mathrm{cli}}=1-\frac{\sum_{t}\left(Q_{\mathrm{obs}}^{t}-Q_{\mathrm{for}}^{t}\right)^{2}}{\sum_{t}\left(Q_{\mathrm{obs}}^{t}-Q_{\mathrm{cli}}^{t}\right)^{2}}$

where $t$ is the time interval, $Q_{\text {obs }}$ is daily discharge observed at stream gauge stations, $Q_{\text {for }}$ is forecasted discharge, $Q_{\text {cli }}$ is the climatological value of discharge on day $t$ computed from observations. $\mathrm{SS}_{\mathrm{cli}}$ ranges from $-\infty$ to 1 (optimum) and positive values show an improvement over a forecast based on climatology.

\section{Results and discussion}

\subsection{In situ discharge assimilation}

We start our analysis evaluating the sensitivity of the DA scheme performance to some of its parameters, as presented in Fig. 1. The objective of such examination is to verify which parameters are the most important ones and if the DA performance is improved by using values of these parameters that are different from the first guess ones based on previous studies (see Sect. 3.4.). The configuration of Exp. 1a was used, where in situ discharge data were assimilated. Results were evaluated in terms of mean changes in root-meansquared error ( $\Delta \mathrm{rms})$ between observed and simulated discharges, computed for two samples, the first including stream gauges used for data assimilation and the latter only the validation ones. Larger decreases in the rms error indicate better performance of the DA scheme.
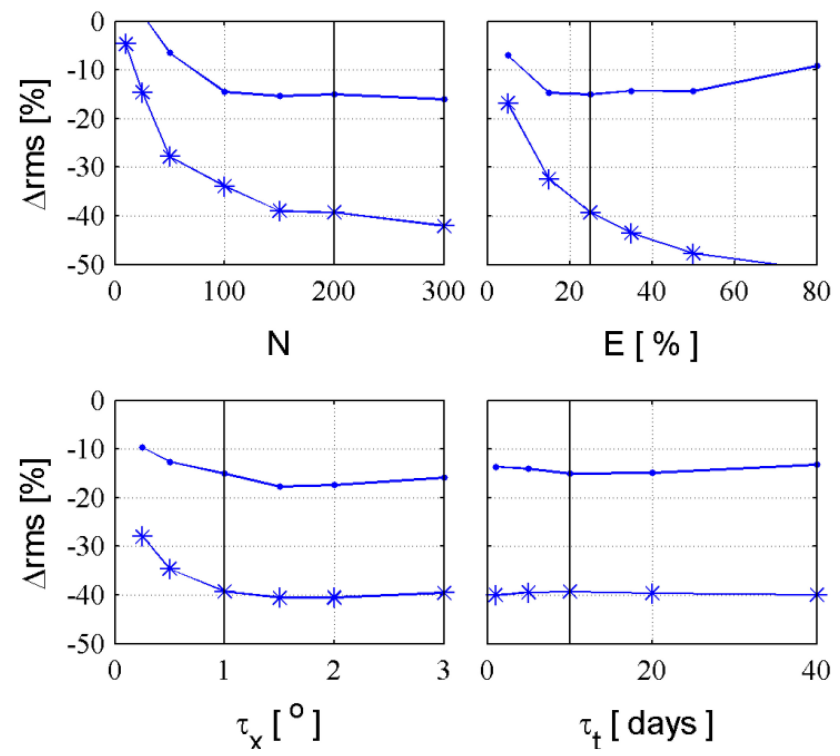

Fig. 1. Sensitivity tests of DA scheme parameters. Mean change in root-mean-square error $(\Delta \mathrm{rms})$ for the assimilation (line with stars) and validation (line with dots) stream gauges as function of ensemble size $(N)$, precipitation relative error $(E)$ and spatial $\left(\tau_{\mathrm{x}}\right)$ and temporal $\left(\tau_{\mathrm{t}}\right)$ decorrelation lengths of precipitation errors. First guess values are represented by the black line.

According to the analysis, the DA scheme strongly depends on the ensemble size $N$. Small $N$ values produce small improvements in discharge results and larger values enhance the DA performance (smaller $\Delta$ rms values), although the improvement rate is small for $N$ values larger than 150 members. Such behaviour is possibly due to numerical reasons, since a larger $N$ enable a better sampling of model covariance errors from the ensemble, as discussed by Evensen (2009). The DA scheme is also very sensitive to precipitation relative error $E$ and increasing $E$ values improves DA performance. However, if $E$ is larger than $50 \%, \Delta \mathrm{rms}$ increases in validation sites causing worse results (see Fig. 1). Possibly, larger precipitation errors cause larger model uncertainty and consequently the DA scheme gives more weight to observations, but it starts to degrade model results at different locations after some point. A moderate dependence to the $\tau_{\mathrm{x}}$ parameter was found and spatial correlation of precipitation errors showed to be of importance, since the performance degrades for smaller decorrelation lengths. The best results were obtained for $1.5^{\circ}$ for both the assimilation and validation samples. Finally, a weak sensitivity to the $\tau_{\mathrm{t}}$ parameter was found, which indicates that considering temporal correlation in precipitation errors is not as important as spatial correlation.

Based on the sensitivity tests, we used the following new parameter values for the further experiments: $N=200$ (unchanged), $E=50 \%, \tau_{\mathrm{x}}=1.5^{\circ}$ and $\tau_{\mathrm{t}}=10$ days (unchanged). However, it is noteworthy that these parameter values related 


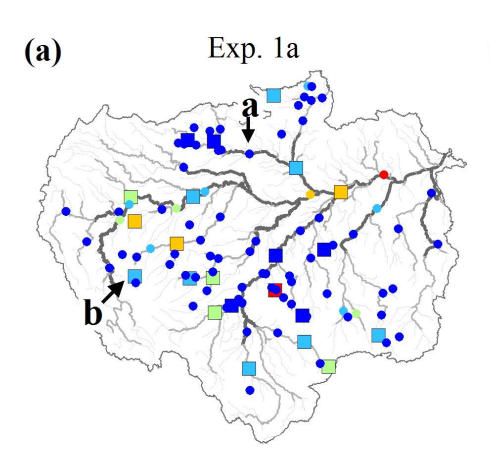
In situ discharge assimilation

(b) Exp. 1b

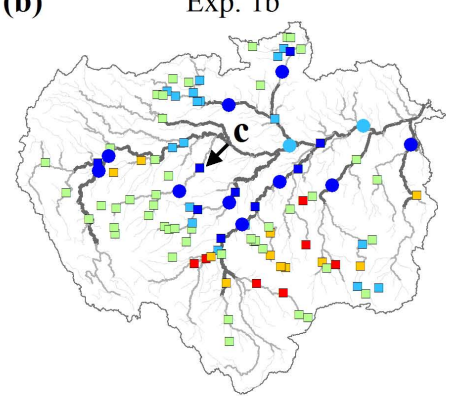

(c) $\quad$ Exp. 1c

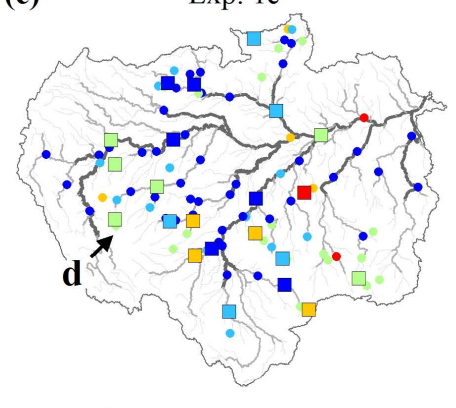

$\Delta \mathbf{r m s}$

$<-30 \% \bigcirc-30--10 \% \bigcirc-10-10 \% \bigcirc 10-30 \%$

$>30 \%$

- Assimilation घValidation

Fig. 2. Evaluation of in situ discharge assimilation. Spatial distribution of change in root-mean-square error ( $\Delta \mathrm{rms})$ in stream gauges used for data assimilation (circles) and validation (squares) considering the assimilation of (a) almost all gauges (Exp. 1a), (b) only 12 gauges (Exp. 1b) and (c) almost all gauges but without log transformation (Exp. 1c).

Table 1. Summary of the performance of in situ discharge data assimilation (Exp. 1): median Nash and Suttcliffe index ( $\left.E_{\mathrm{NS}}\right)$ in simulation (Open-loop) and assimilation (EnKF) modes and mean change in root-mean-square error $(\Delta \mathrm{rms})$.

\begin{tabular}{|c|c|c|c|c|c|c|c|}
\hline & & \multicolumn{2}{|c|}{ Exp. $1 \mathrm{a}^{\mathrm{b}}$} & \multicolumn{2}{|c|}{ Exp. $1 b^{c}$} & \multicolumn{2}{|c|}{ Exp. 1c $\mathrm{c}^{\mathrm{d}}$} \\
\hline \multicolumn{2}{|l|}{ Sites } & $E_{\mathrm{NS}}$ & $\Delta \mathrm{rms}(\%)$ & $E_{\mathrm{NS}}$ & $\Delta \mathrm{rms}(\%)$ & $E_{\mathrm{NS}}$ & $\Delta \mathrm{rms}(\%)$ \\
\hline \multirow{2}{*}{ All } & Open-loop & 0.68 & - & 0.68 & - & 0.68 & - \\
\hline & EnKF & 0.93 & -42 & 0.72 & -8 & 0.85 & -25 \\
\hline \multirow{2}{*}{ Assimilation } & Open-loop & 0.71 & - & 0.89 & - & 0.71 & - \\
\hline & EnKF & 0.94 & -49 & 0.98 & -51 & 0.88 & -29 \\
\hline \multirow{2}{*}{ Validation } & Open-loop & 0.60 & - & 0.65 & - & 0.60 & - \\
\hline & EnKF & 0.73 & -16 & 0.67 & -3 & 0.67 & -10 \\
\hline \multirow{2}{*}{ Large rivers $^{\mathrm{a}}$} & Open-loop & 0.79 & - & 0.79 & - & 0.79 & - \\
\hline & EnKF & 0.94 & -34 & 0.87 & -23 & 0.95 & -40 \\
\hline
\end{tabular}

${ }^{\mathrm{a}}$ Stream gauges located at rivers reaches with upstream drainage area larger than $10^{5} \mathrm{~km}^{2}$. ${ }^{\mathrm{b}}$ Exp. $1 \mathrm{a}-$ data assimilation using discharge from $80 \%$ of the stream gauges. ${ }^{c}$ Exp. $1 \mathrm{~b}$ - data assimilation using discharge from $10 \%$ of the stream gauges. ${ }^{d}$ Exp. 1c - equal Exp. 1a but without transforming discharge into the log space.

to precipitation errors, although providing better results for data assimilation, may not realistically represent errors in the TRMM Merge dataset. For example, Tian and PetersLidard (2010) developed a global map of errors in daily satellite-based precipitation estimates that show features not represented here: errors that are spatially and seasonally variable and that decrease with precipitation rate (from $\sim 100 \%$ at $1 \mathrm{~mm} \mathrm{~d}^{-1}$ to $\sim 20 \%$ at $100 \mathrm{~mm} \mathrm{~d}^{-1}$ in South America). On the other hand, the DA scheme had better performance with $E=50 \%$, which is only slightly larger than the values found by Tian and Peters-Lidard (2010) for the Amazon region, that ranges from $\sim 20 \%$ to $\sim 70 \%$. A possible explanation is the consideration of that model uncertainty coming from precipitation errors and neglecting other sources such as parameter and model structural errors (Liu and Gupta, 2007), making $E$ larger. Therefore, and since the first guess values were not fully justified in the previous studies (Andreadis and Letten- maier, 2006; Clark et al., 2008), we preferred to use the parameter values where the DA scheme performs better.

We first evaluate results from the Exp. 1a. The DA scheme improves results by decreasing model errors in almost all stream gauges (blue sites in Fig. 2a), including both assimilation and validation sites. On average, $E_{\mathrm{NS}}$ values increase from 0.71 to 0.94 and the rms error decreases by $49 \%$ (Table 1). For example, at an assimilation site located on the Negro River (Fig. 3a), when the EnKF is used, the discharge estimates are much closer to observations if compared with the open-loop simulation. The $E_{\mathrm{NS}}$ index increases from 0.62 to 0.91 and the rms error decreases by $51 \%$. Similarly, results also improve at validation sites, although with a smaller degree, and the $E_{\mathrm{NS}}$ index increases from 0.60 to 0.73 , with a reduction in rms error of $-16 \%$ (Table 1 ), as illustrated at a validation site located at upper Juruá River basin (Fig. 3b). Such results demonstrate that the DA scheme improves model discharge estimates, not only at sites where 
(a)

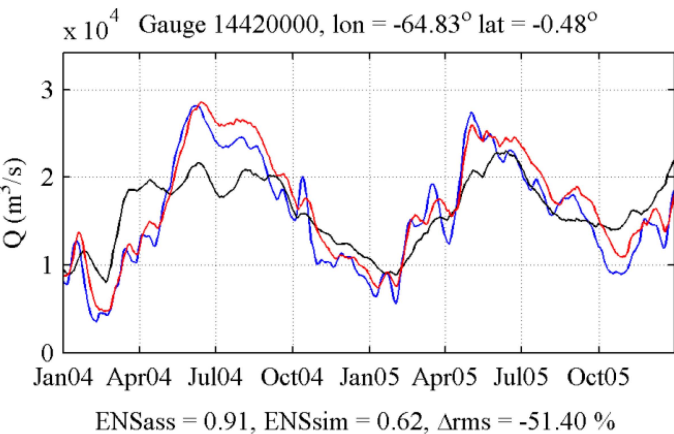

(c)

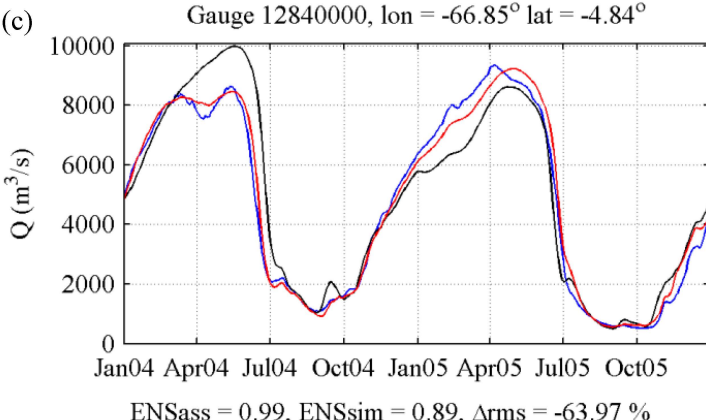

(b)

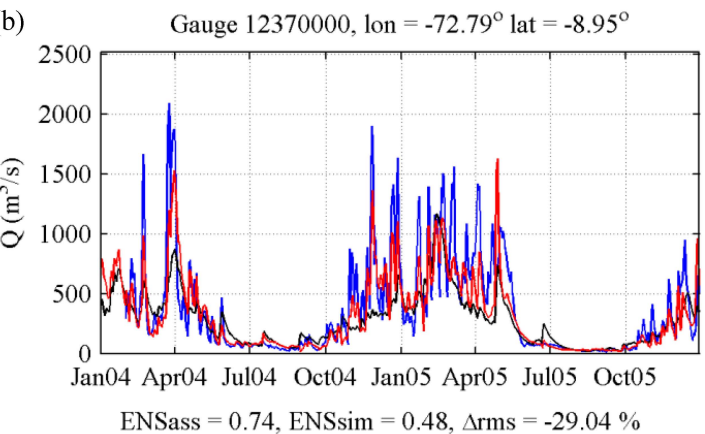

(d)

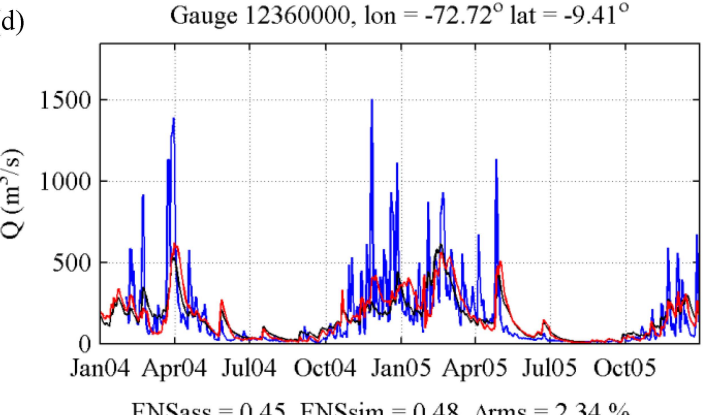

Fig. 3. Discharge derived from in situ observation (blue line), open-loop simulation (black line) and EnKF simulation (red line) at (a) Negro River (assimilation site, Exp. 1a), (b) upper Juruá River (validation site, Exp. 1a), (c) lower Juruá River (validation site Exp. 1b) and upper Juruá River (assimilation site, Exp. 1c). Site are indicated Fig. 2.

data were assimilated but possibly at ungauged rivers reaches as well.

In Exp. 1b, results improve at assimilation sites $-E_{\mathrm{NS}}$ increases from 0.89 to 0.98 and the rms error decreases by $50 \%$ (Table 1). However, since data from only a few gauges were assimilated, there is no important improvement $(\Delta \mathrm{rms}=-3 \%)$ if all validation sites are examined together. As expected, according to Fig. $2 \mathrm{~b}$ the DA scheme improves discharge estimates mostly at large rivers (e.g. Fig. 3c), where $E_{\mathrm{NS}}$ increases from 0.79 to 0.87 while $\Delta \mathrm{rms}$ equals $-23 \%$. But at smaller rivers, in most cases the DA scheme has minor effect on simulated discharges (green squares at Fig. 2b) or in some cases it degrades results.

In previous studies conducted over smaller basins (e.g. in Clark et al., 2008; and in others summarised by Lee et al., 2012), the attempt to transfer information to neighbour or upstream ungauged river reaches was unsuccessful and corrupted model results, while in our case (Exp. 1b) the DA scheme degraded model outputs mostly at smaller basins and improved results at larger rivers. Such behaviour possibly happens because the state estimation in distributed hydrological models is subject to overfitting due to the large dimensionality of the model state space, and consequently, when limited data is available, the data assimilation may update state variables at some lumped fashion such as the sub-basin scale, as explained by Lee et al. (2012).
Finally, we compare the use (Exp. 1a) or not (Exp. 1c) of the transformation of discharge values into the log space before data assimilation. The performance of the DA scheme degrades if the log transformation is not used, and in this case $\Delta \mathrm{rms}$ increases to $-29 \%$ and $-10 \%$ for the assimilation and validation samples respectively, instead of the $-49 \%$ and $-16 \%$ values obtained in the Exp. 1a. Clark et al. (2008) argue that the EnKF with log transformation performs better because relationships between streamflow and model states are nonlinear and state updates are exceptionally large when differences between model and observed values are high. However, the worst performance was observed mostly at smaller river reaches (see Fig. 2c) as illustrated in Fig. 3c. Also, DA performs better at gauging stations in large rivers and $\Delta \mathrm{rms}$ increases from $-34 \%$ (Exp. 1a) to $-40 \%$ (Exp. 1c). Apparently, when the log transformation is not used, the DA scheme gives more weight to large discharge values $\left(\sim 10^{3}\right.$ to $\left.\sim 10^{5} \mathrm{~m}^{3} \mathrm{~s}^{-1}\right)$ at large rivers while observations at the smaller ones $\left(<\sim 10^{3} \mathrm{~m}^{3} \mathrm{~s}^{-1}\right)$ are not fully taken into account. These results indicate the importance of using the log space transformation also to deal with very different discharge magnitudes, including the ones arising from different spatial scales but also concerning to flood and drought flows. 


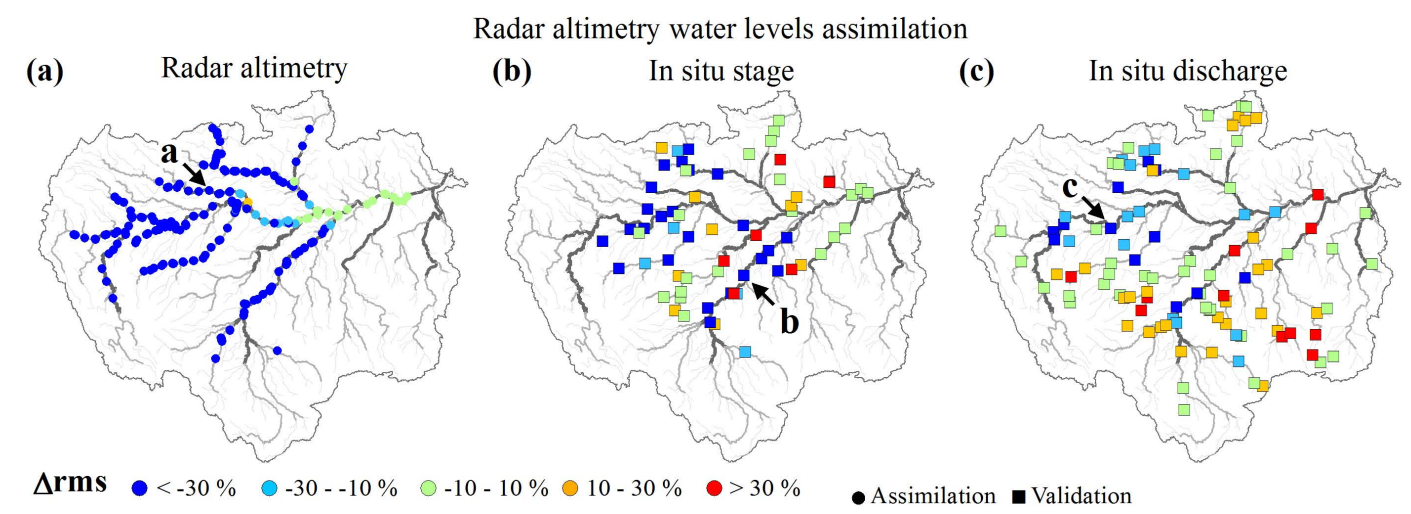

Fig. 4. Evaluation of ENVISAT radar altimetry data assimilation. Spatial distribution of change in root-mean-square error $(\Delta$ rms) at (a) altimetry stations used for data assimilation and stream gauges with (b) stage and (c) discharge data used for verification.

\subsection{Radar altimetry data assimilation}

In this section, the assimilation of water levels derived from ENVISAT altimetry is evaluated (Exp. 2). Stage and discharge data observed at in situ gauging stations were used for validation purposes.

The DA scheme improves water level simulations at altimetry stations used for assimilation (Fig. 4a), as illustrated in Fig. 5a. On average, rms decreases by $56 \%$ and $E_{\mathrm{NS}}$ values increase from 0.66 to 0.96 (Table 2). Simulated water level accuracy also increases when compared to in situ stage data $(\Delta \mathrm{rms}=-13 \%)$. However, the improvement is more evident if only gauging stations located at rivers where altimetry data were examined (Figs. $4 \mathrm{~b}$ and $5 \mathrm{~b}$ ). In this case, mean $\Delta \mathrm{rms}$ equals $-43 \%$ and $E_{\mathrm{NS}}$ changes from 0.75 to 0.94 (Table 2), similar to what was obtained at altimetry stations. At other sites, the DA scheme has a minor effect on simulated water levels or even degrades results in some cases.

Similar results were found for the in situ discharge validation sample (Fig. 4c). Assimilating water level data improves discharge estimates $(\Delta \mathrm{rms}=-15 \%)$ mostly at the same rivers in which altimetry data is available (e.g. Fig. 5c). But it also degrades results at some of the other river reaches. The minor improvement of discharge estimates when water levels are assimilated may related to the fact that water level errors are not only related to stream flow or precipitation errors, but also to river-floodplain geometry parameters, as discussed by Paiva et al. (2013b). But this kind of model uncertainty was not considered by the DA scheme. Consequently, at river reaches where the model already provided accurate discharge estimates but wrong water level results, altimetry data assimilation corrects water levels but it can degrade discharge results. Some possible alternatives to improve model discharge results from radar altimetry assimilation could be: (i) the simultaneous assimilation of discharge and water level data; (ii) the assimilation of altimetry-based discharge data (tested in Sect. 4.3); (iii) representing the uncertainty of model parameters (e.g. river-floodplain geome- try) in the DA scheme; (iv) assimilation of altimetry data to first retrieve better river-floodplain geometry parameters (e.g. Durand et al., 2008, 2010b); or (v) assimilation future SWOT data (Durand et al., 2010a), that will provide additional information such as water surface slope.

Furthermore, the DA scheme can degrade results in some reaches where no data were assimilated. Such a problem is possibly caused by spurious correlations in the model covariance matrix from the EnKF due to a poor sampling from the ensemble. Aiming to avoid spurious correlations, methods such as covariance localisation or local analysis (Sakov and Bertino, 2010) could be used to constrain the influence of observations based on distance criteria as already used in atmospheric or ocean applications. However, in our view, a particular localisation criteria should be developed for hydrological applications, since the correlation between the model states can be a function of an Euclidean distance in some cases (e.g. soil moisture) or in others, of a distance measured following the rivers' path (e.g. river discharge and water levels).

Results from this experiment demonstrate that the assimilation of radar altimetry data into large scale hydrologic models can improve simulations, mainly in terms of water levels but also in discharge to a minor degree. Even though ENVISAT data is provided at a 35 day temporal resolution, its assimilation can improve model results at a daily basis as illustrated in Fig. 5b and c possibly due to the low temporal variability of Amazonian hydrographs and the fact that ENVISAT measurements are non-simultaneous.

\subsection{Assimilation of discharge series based on satellite altimetry}

In the last DA experiment (Exp. 3), we evaluate the assimilation of discharge data derived from ENVISAT water level. Therefore, the data assimilated into the model has the same high spatial coverage and low temporal sampling as altimetry water levels have, but it also contains discharge informa- 
Table 2. As Table 1 but for Exp. 2.

\begin{tabular}{|c|c|c|c|c|}
\hline & Sites & & $E_{\mathrm{NS}}$ & $\Delta \mathrm{rms}(\%)$ \\
\hline \multirow{6}{*}{ All } & \multirow{2}{*}{ Radar altimetry - Assimilation } & Open-loop & 0.66 & - \\
\hline & & EnKF & 0.96 & -56.0 \\
\hline & \multirow{2}{*}{ In situ stage - Validation } & Open-loop & 0.64 & - \\
\hline & & EnKF & 0.74 & -13 \\
\hline & \multirow{2}{*}{ In situ discharge - Validation } & Open-loop & 0.68 & - \\
\hline & & EnKF & 0.68 & 1 \\
\hline \multirow{4}{*}{$\begin{array}{l}\text { Inside ENVISAT } \\
\text { domain }^{\mathrm{a}}\end{array}$} & \multirow{2}{*}{ In situ stage - Validation } & Open-loop & 0.75 & - \\
\hline & & EnKF & 0.94 & -44 \\
\hline & \multirow{2}{*}{ In situ discharge - Validation } & Open-loop & 0.79 & - \\
\hline & & EnKF & 0.86 & -15 \\
\hline
\end{tabular}

${ }^{a}$ Upstream and downstream at least one altimetry station.

Table 3. As Table 1 but for Exp. 3.

\begin{tabular}{|c|c|c|c|c|}
\hline & Sites & & $E_{\mathrm{NS}}$ & $\Delta \mathrm{rms}(\%)$ \\
\hline \multirow{2}{*}{ All } & Altimetry discharge - Assimilation & $\begin{array}{l}\text { Open-loop } \\
\text { EnKF }\end{array}$ & $\begin{array}{l}0.62 \\
0.79\end{array}$ & $\begin{array}{r}- \\
-23\end{array}$ \\
\hline & In situ discharge - Validation & $\begin{array}{l}\text { Open-loop } \\
\text { EnKF }\end{array}$ & $\begin{array}{l}0.68 \\
0.72\end{array}$ & $\begin{array}{r}- \\
-5\end{array}$ \\
\hline $\begin{array}{l}\text { Inside ENVISAT } \\
\text { domain }^{\mathrm{a}}\end{array}$ & In situ discharge - Validation & $\begin{array}{l}\text { Open-loop } \\
\text { EnKF }\end{array}$ & $\begin{array}{l}0.76 \\
0.80\end{array}$ & $\begin{array}{r}- \\
-15\end{array}$ \\
\hline
\end{tabular}

a Upstream and downstream at least one altimetry station.

tion which is the most important hydrological variable of the model. In situ discharge data were also used for validation.

The DA scheme was able to assimilate altimetry-based discharges increasing the agreement between these observations and model results in most of the altimetry stations (Fig. 6a), as exemplified in Fig. 7a. In average, the rms error between altimetry-based discharges and model results decreased $23 \%$ (Table 3), which represents a smaller improvement if compared to the assimilation of in situ discharge $(\Delta \mathrm{rms}=-49 \%$ in Exp. 1a). Since observation errors are larger in the altimetry-based discharges, the DA scheme gives more weight to background model results and updated discharge values are not so close to measurements. The comparison of model results with in situ discharge data (Fig. 6b) shows that errors decrease mostly at gauging stations located at rivers where altimetry data were assimilated (e.g. Fig. 7b). At these sites, $E_{\mathrm{NS}}$ changes from 0.76 to 0.80 and the mean $\Delta \mathrm{rms}$ is $-14 \%$ (Table 3), which is comparable to the improvement obtained in the altimetry data assimilation (Exp. 2, Table 2) over discharge results $(\Delta \mathrm{rms}=-15 \%)$, but smaller than the enhancement of water level results $(\Delta \mathrm{rms}=-44 \%)$. Moreover, similarly to Exp. 2, at gauging stations located outside the assimilation domain, the DA scheme has a minor effect on simulated discharge or degrades results in some cases.

Results from this section show the potential of assimilating discharge data derived from satellite altimetry into large scale hydrological models instead of in situ discharge or satellite water levels, even though such data has lower temporal resolution and accuracy if compared to data gathered at in situ gauging stations.

\subsection{Prospects of streamflow forecasting}

We now assess the potential of a large scale hydrologichydrodynamic model coupled with a DA scheme to provide streamflow forecasts in the Amazon basin. Since hydrological initial states governs discharge predictability at the large Amazonian rivers (discussed by Paiva et al., 2012), we have chosen to generate forecasts starting with initial states gathered by the DA scheme and then using the ensemble streamflow prediction approach - ESP (Day, 1985), where the model is run forced by an ensemble of observed meteorological data from past years. Since this is a first attempt, we have chosen to evaluate forecasts using only the DA scheme configuration from Exp. 1b, where the model is updated using discharge data from 12 gauging stations located on the Amazon and its main tributaries. 
(a)

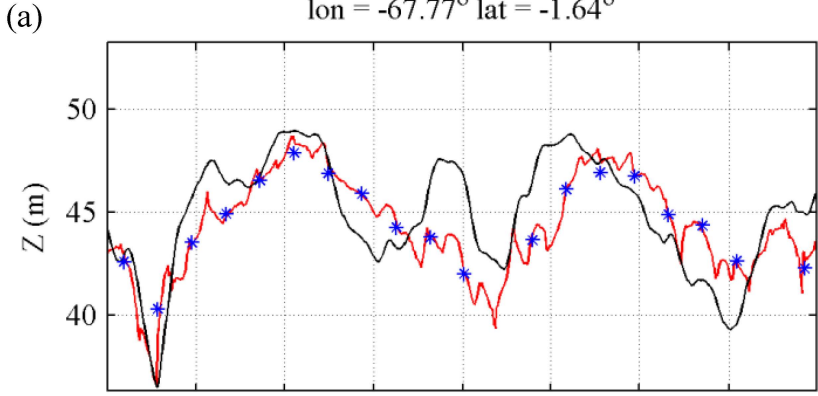

Jan04 Apr04 Jul04 Oct04 Jan05 Apr05 Jul05 Oct05

ENSass $=0.96$, ENSsim $=-0.29, \Delta \mathrm{rms}=-82.05 \%$

(b)

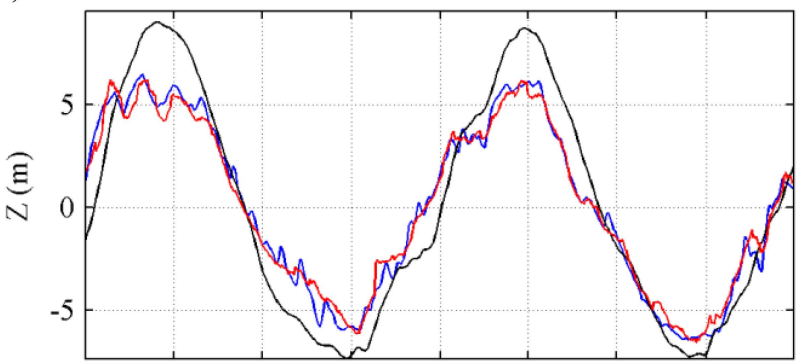

Jan04 Apr04 Jul04 Oct04 Jan05 Apr05 Jul05 Oct05

ENSass $=0.99$, ENSsim $=0.83, \Delta \mathrm{rms}=-71.03 \%$

(c) $\times 10^{4}$ Gauge 10100000 , lon $=-69.93^{\circ}$ lat $=-4.25^{\circ}$

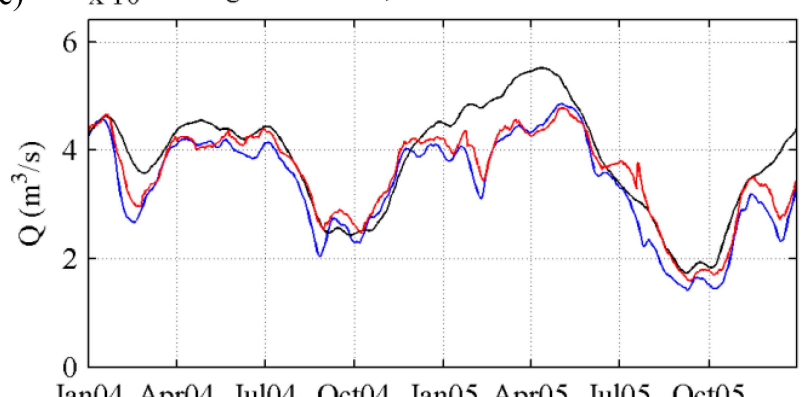

ENSass $=0.90$, ENSsim $=0.55, \Delta \mathrm{rms}=-52.43 \%$

Fig. 5. Observation (blue line), open-loop simulation (black line) and EnKF simulation (red line) at (a) Japurá River altimetry site, (b) Madeira River in situ stage site (c) Solimões River in situ discharge site. Sites are indicated in Fig. 4.

We first evaluate hindcast forecasts at the Solimões/Amazon main stem, including upper Solimões River at Tamishiyacu, Solimões River at Manacapuru and Amazon River at Óbidos (Fig. 8). Notice that these gauges were used by the DA scheme. The model was able to forecast discharges with relatively high accuracy even for very large lead times (90 days). In all cases, forecasts are markedly better than simply using discharge climatology, as shown by positive values of $\mathrm{SS}_{\text {cli }}$ skill score (Fig. 8). As expected, the agreement between model values and
Radar altimetry discharge assimilation

(a) Radar altimetry discharge

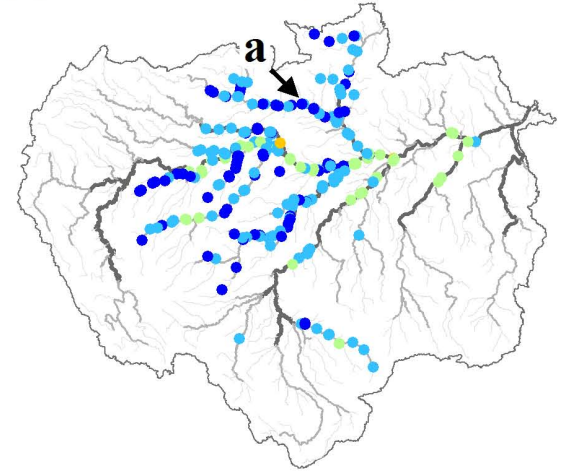

(b) In situ discharge

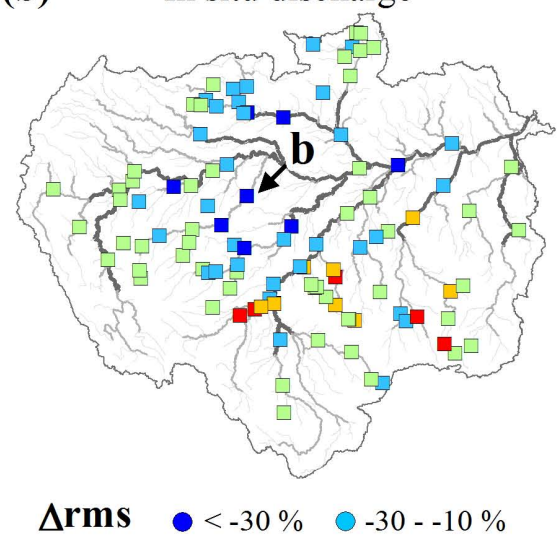

$-10-10 \% \bigcirc 10-30 \% \bigcirc 30 \%$

- Assimilation validation

Fig. 6. Evaluation of ENVISAT radar altimetry discharge assimilation. Spatial distribution of change in root-mean-square error $(\Delta \mathrm{rms})$ at (a) altimetry stations used for data assimilation and (b) stream gauges with discharge data used for validation.

observations decreases as function of lead time and, for example, $\mathrm{SS}_{\mathrm{cli}}$ decreases from 0.90 to 0.49 for forecasts 10 and 90 days ahead at Óbidos station. But it remains very high, showing that it would be possible to produce accurate forecasts at the Amazon main river for even larger lead times. Model performance also increases from the upper to the lower part of the Solimões/Amazon River, and at the same time, the spread of the ESP ensemble at large lead times increases upstream and decreases downstream. Such behaviour is explained by the fact that in larger rivers, the hydrological predictability is much more influenced by the current volumes of water stored upstream than by future precipitation forcing, as discussed by Paiva et al. (2012).

Analysis from Fig. 8 also demonstrates that the model successfully predicted the severe 2005 drought at the Solimões/Amazon main stem. At this year, discharges dropped $\sim 1$ month earlier than normal (Fig. 8 ) and river levels fell to historically low levels causing navigation to be sus- 

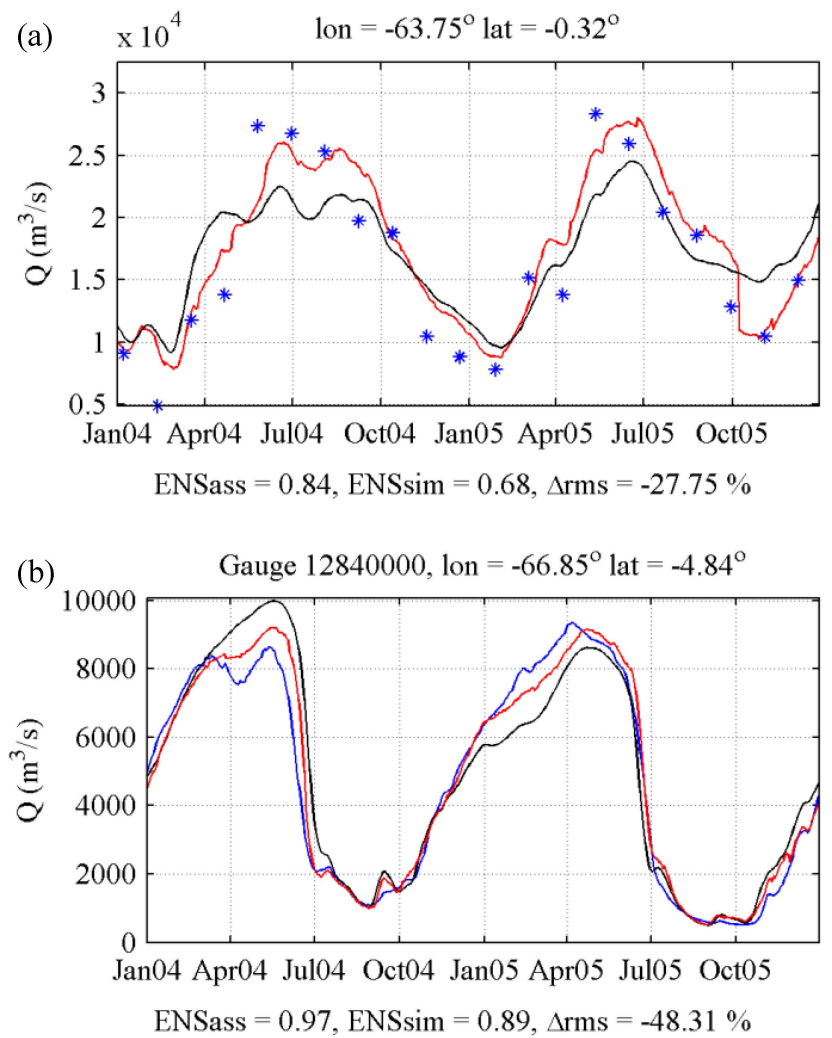

Fig. 7. Observation (blue line), open-loop simulation (black line) and EnKF simulation (red line) of discharge at (a) Negro River altimetry site and (b) Juruá River in situ site. Sites are indicated in Fig. 6.

pended (Marengo et al., 2008). Even so, the model was able to predict this low flows $\sim 90$ days ahead.

We now evaluate forecasts at gauging stations located all over the Amazon basin. Forecasts for a smaller lead time of 5 days or even 15 days (Fig. 9a and b) were relatively accurate with positive $\mathrm{SS}_{\mathrm{cli}}$ values at several gauging stations located at both upstream and downstream rivers. However, the quality of the forecasts decreased as a function of lead time (30 and 90 days, Fig. 9c and d). It becomes very poor at smaller rivers and remains meaningful with positive $\mathrm{SS}_{\mathrm{cli}}$ values mainly at gauging stations with large draining areas. For 90 days lead time, $\mathrm{SS}_{\mathrm{cli}}$ index remains positive at almost all stations along the Solimões/Amazon main stem and in some of the main tributaries. This behaviour is also illustrated at Fig. 10. $\mathrm{SS}_{\mathrm{cli}}$ values are usually higher at gauging stations located in rivers draining large areas and decrease with lead time. For instance, if only stations gauging rivers with drainage area larger than $10^{5} \mathrm{~km}^{2}$ or $4 \times 10^{5} \mathrm{~km}^{2}$ are considered, on average, forecasts remain better than climatology $\left(\mathrm{SS}_{\mathrm{cli}}>0\right)$ up to $\sim 15$ and $\sim 25$ days lead time, respectively. On the other hand, if only the largest rivers are taken into account $\left(>10^{6} \mathrm{~km}^{2}\right), \mathrm{SS}_{\mathrm{cli}}$ values are high and always positive, which demonstrates the good performance of
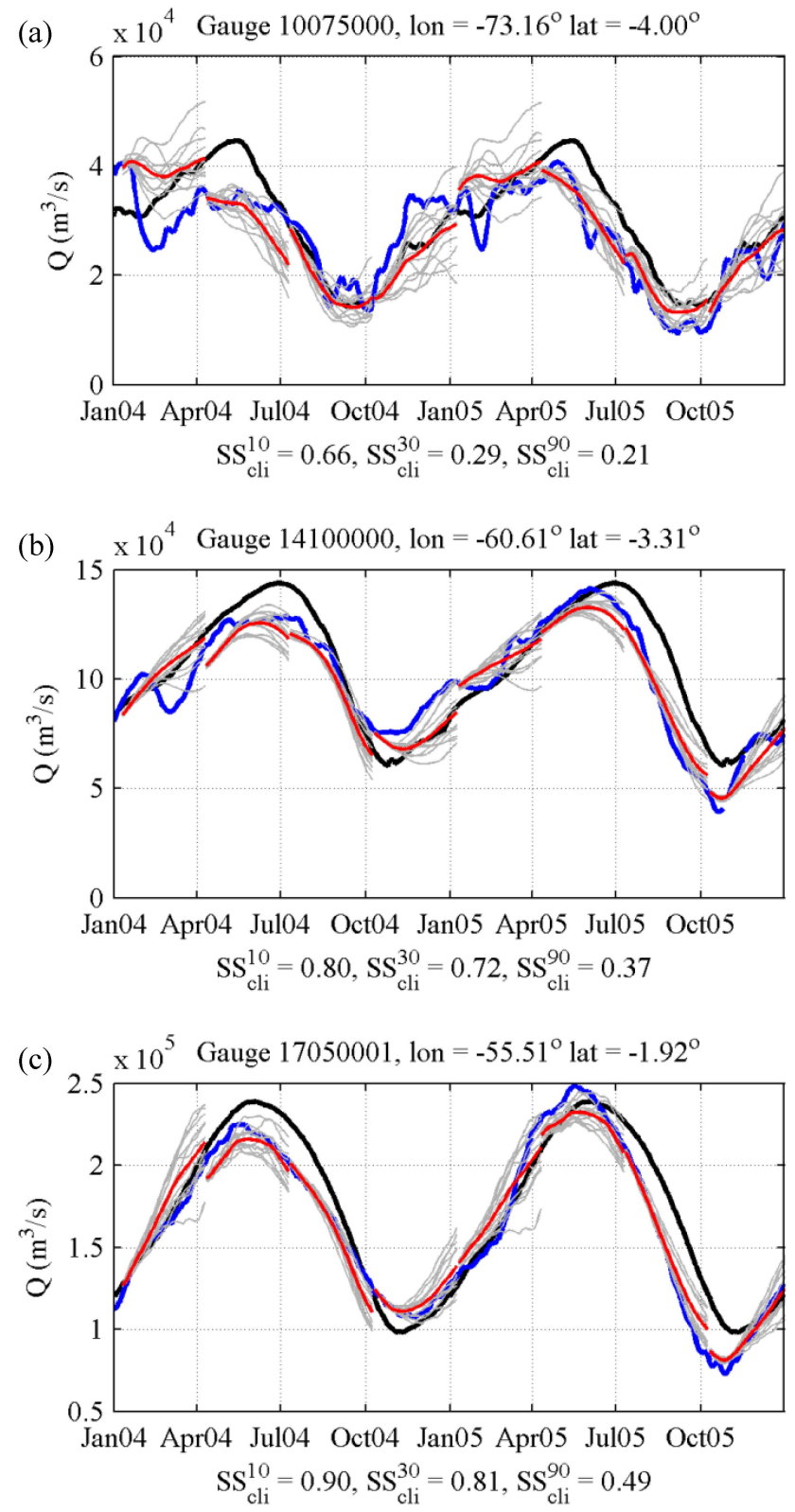

Fig. 8. Evaluation of streamflow forecasts. Observed (blue), climatological (black) discharges, ensemble forecasts (grey) together with ensemble mean (red) at (a) Upper Solimões River at Tamishiyacu, (b) Solimões River at Manacapuru and (c) Amazon river at Óbidos. Presented forecasts started each 10 January, April, July and October. Sites are indicated in Fig. 9. 

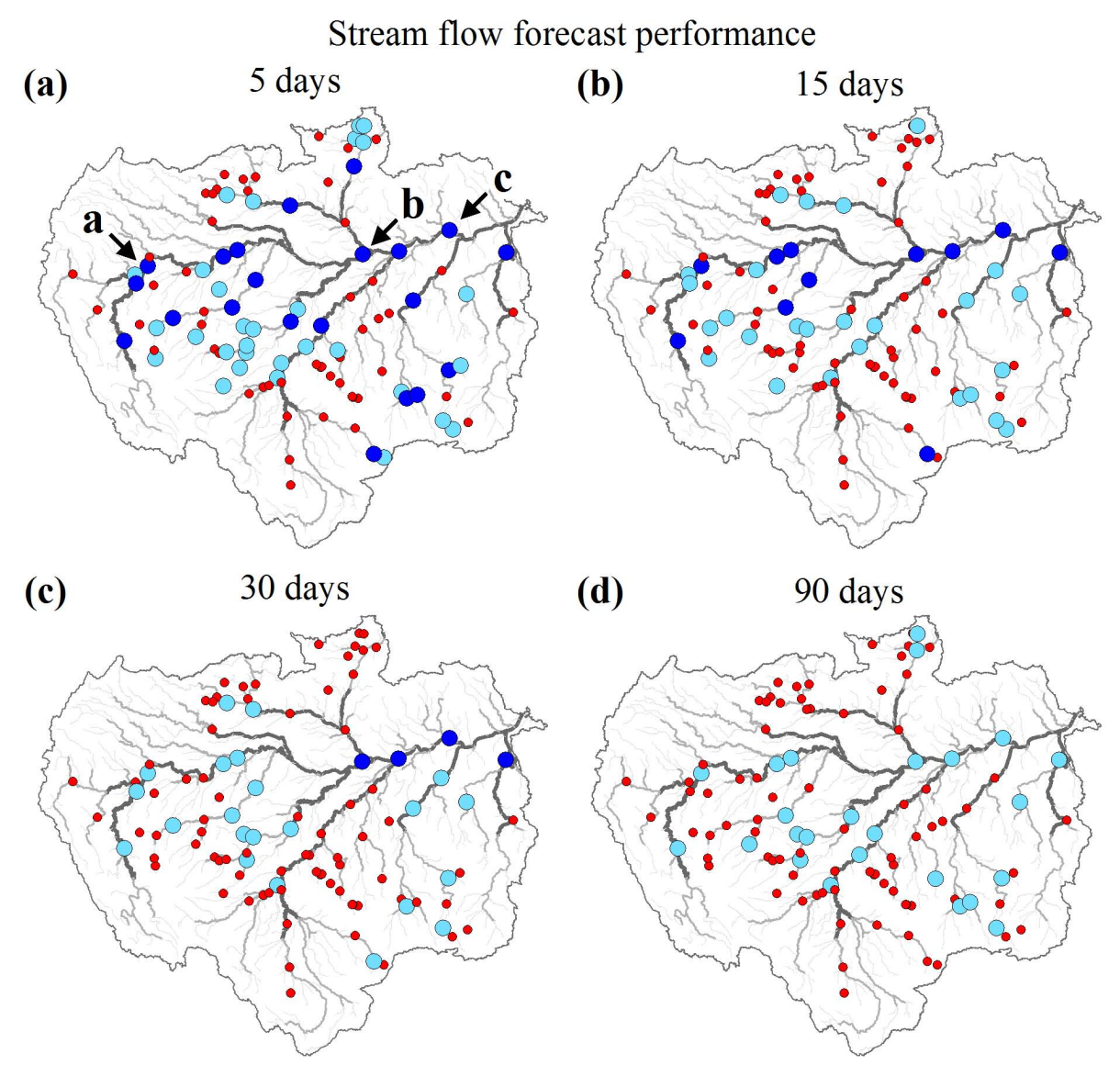

(d) 90 days

SScli $0.5-1.0 \bigcirc 0.0-0.5 \odot<0.0$

Fig. 9. Evaluation of streamflow forecasts. Spatial distribution of the skill score $\mathrm{SS}_{\mathrm{cli}}$ for (a) 5, (b) 15, (c) 30 and (d) 90 days lead time.

the model forecasts. $\mathrm{SS}_{\mathrm{cli}}$ is also high at stream gauges used for data assimilation where forecasts are usually better, $\mathbf{S S}_{\mathrm{cli}}$ is close to one for small lead times, as expected, and becomes negative after $\sim 55$ days.

\section{Summary and conclusions}

We presented the development and evaluation of a data assimilation scheme for both gauged and satellite altimetrybased discharge and water levels into a large scale hydrologic-hydrodynamic model of the Amazon River basin using the Ensemble Kalman Filter - EnKF. We also evaluated hindcast forecasts based on this system using the ensemble streamflow prediction approach, where the model was forced by an ensemble of past precipitation forcing from TRMM mission.

According to our results, the data assimilation scheme performed well in assimilating in situ and remotely sensed discharge and water levels into the large scale hydrologichydrodynamic model. The assimilation of in situ discharge showed that EnKF can improve discharge estimates at assimilation gauges, but differently from previous studies at smaller basins (e.g. Clark et al., 2008; and others summarised by Lee et al., 2012), also transfer information to ungauged rivers by improving results at validation sites, although with a smaller degree. The assimilation of discharge data at a reduced number of gauging stations located at larger rivers improves results mostly at the large reaches but it degrades results at some smaller basins. Also, the transformation of discharge measurements into the log space proved to be important to deal with very different discharge magnitudes arising from different spatial scales or from contrasting flood and recession flows.

The assimilation of satellite altimetry data improved model water levels, and also discharges to a minor degree, mostly at the same river reaches where altimetry stations are located. Assimilating altimetry-based discharge also improved model estimates, although to a minor degree if compared to the in situ discharge assimilation, probably due to the larger errors in remotely sensed observations. However, in both cases, even though radar altimetry data has low temporal resolution (35 days), its assimilation can improve model results at a daily basis, possibly due to its higher spa- 


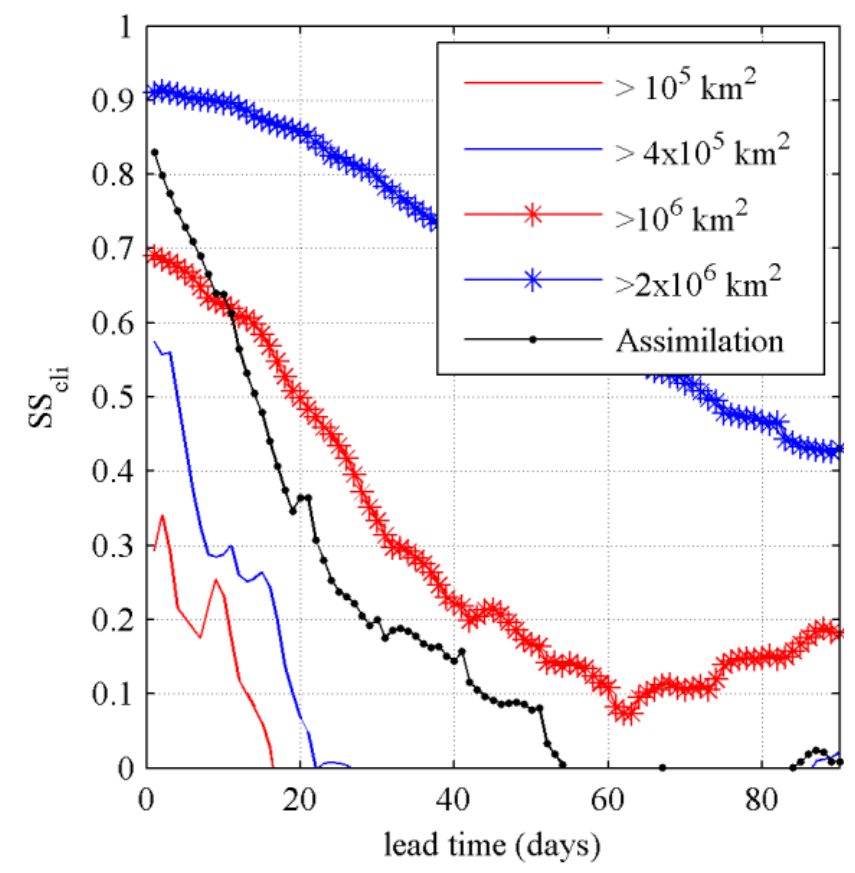

Fig. 10. Median skill score $\mathrm{SS}_{\mathrm{cli}}$ of stream flow forecasts at gauging stations as function of lead time. Different curves show results considering gauges with different drainage areas (red and blue lines) and only gauges used for data assimilation (black line with dots).

tial resolution and the low temporal variability of Amazonian hydrographs.

The sensitivity analysis of the parameter from the DA scheme highlighted the importance of the magnitude of precipitation errors and that of their spatial correlation, while temporal correlation showed to be dispensable.

The deterioration of model performance at some unmonitored reaches may be due to the large dimensionality of state space in distributed hydrological models compared to the available information. Consequently, data assimilation may update state variables at some lumped fashion such as the sub-basin scale, as explained by Lee et al. (2012). This problem can be also due to spurious correlations that can arise by numerical reasons and could be avoided by using proper spatial localisation methods (e.g. Sakov and Bertino, 2010) developed for hydrological applications to constrain the influence of measurements. Additionally, the DA scheme could benefit from a better characterisation of model errors, where not only precipitation but other sources of uncertainty, such as in model parameters and structure could be included, as suggested by Liu et al. (2012).

Although limitations still exist, results are encouraging. This kind of DA scheme could also be easily employed to other similar regional/global scale hydrological models (e.g. Yamazaki et al., 2011; Decharme et al., 2011; Alfieri et al., 2013). It has also the potential to improve by assimilating remotely sensed water levels gathered by other satellite missions as the existing ones, or the altimetry missions to be launched in the coming years by the European Spatial Agency ESA, namely the Sentinel-3 constellation and the forthcoming SWOT mission (Durand et al., 2010a). Moreover, the altimetry-based discharge assimilation can improve when better discharge estimates become available, such as the ones under development for the future SWOT mission (Durand et al., 2010b).

Finally, the model was able to provide relatively accurate streamflow forecasts in the Amazon basin. For smaller lead times ( $\sim 5$ to 15 days), forecasts agreed with observations in lots of gauging stations and for larger lead times $(>30$ days) they remained meaningful mostly at larger rivers. Forecasts were usually better at stream gauges used for data assimilation, especially for smaller lead times. Along the Solimões/Amazon main stem, forecast were highly accurate even for very large lead times (90 days) and the model was capable to successfully predict the record 2005 drought at the Solimões/Amazon River well in advance. These results demonstrate the potential for developing stream flow forecasts with large lead times at the world's large river basins, such as the Amazon, founded on large scale hydrological models based mostly on initial states gathered with proper DA schemes, and using past climate with the ESP approach. Also, results point to the potentiality of providing hydrological forecasts at poorly monitored regions by using mostly remotely sensed information.

Acknowledgements. The authors are grateful for: the financial and operational support from the Brazilian agencies FINEP and ANA ("Projeto de Integração e Cooperação Amazônica para a Modernização do Monitoramento Hidrológico" ICA-MMH) and CNPq-IRD ("Assimilação de Dados de monitoramento Espacial para a análise do regime hidrológico da Bacia Amazônica e a previsão de curto e médio prazos"); the ENVISAT satellite altimetry data supplied by ESA; the TRMM data supplied by NASA and associated agencies; the TRMM Merge data provided by CPTEC/INPE; the discharge and stage data provided by ANA, Hybam, SENHAMI-Peru and SENHAMI-Bolivia; the EnKF Fortran codes provided by Geir Evensen; the support from Fernando Fan in processing precipitation data; as well as for the constructive comments from Adalberto Meller and Jeffrey Neal, and also from Ross Woods (editor from HESS) and two anonymous reviewers.

Edited by: R. Woods

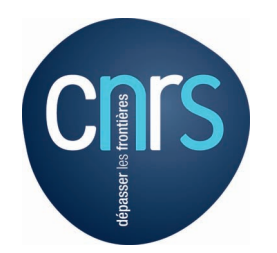

The publication of this article is financed by CNRS-INSU. 


\section{References}

Alfieri, L., Burek, P., Dutra, E., Krzeminski, B., Muraro, D., Thielen, J., and Pappenberger, F.: GloFAS - global ensemble streamflow forecasting and flood early warning, Hydrol. Earth Syst. Sci., 17, 1161-1175, doi:10.5194/hess-17-1161-2013, 2013.

Alsdorf, D. E., Rodriguez, E., and Lettenmaier, D. P.: Measuring surface water from space, Rev. Geophys., 45, RG2002, doi:10.1029/2006RG000197, 2007.

Andreadis, K. M. and Lettenmaier, D. P.: Assimilating remotely sensed snow observations into a macroscale hydrology model, Adv. Water Resour., 29, 872-886, 2006.

Andreadis, K. M., Clark, E. A., Lettenmaier, D. P., and Alsdorf, D. E.: Prospects for river discharge and depth estimation through assimilation of swath-altimetry into a rasterbased hydrodynamics model, Geophys. Res. Lett., 34, L10403, doi:10.1029/2007GL029721, 2007.

Biancamaria, S., Durand, M., Andreadis, K. M., Bates, P. D., Boone, A., Mognard, N. M., Rodriguez, E., Alsdorf, D. E., Lettenmaier, D. P., and Clark, E. A.: Assimilation of virtual wide swath altimetry to improve Arctic river modelling, Remote Sens. Environ., 115, 373-381, 2011.

Chen, J. L., Wilson, C. R., and Tapley, B. D.: The 2009 exceptional Amazon flood and interannual terrestrial water storage change observed by GRACE, Water Resour. Res., 46, W12526, doi:10.1029/2010WR009383, 2010.

Clark, M. P., Rupp, D. E., Woods, R. A., Zheng, X., Ibbitt, R. P., Slater, A. G., Schmidt, J., and Uddstrom, M. J.: Hydrological data assimilation with the ensemble Kalman filter: Use of streamflow observations to update states in a distributed hydrological model, Adv. Water Res., 31, 1309-1324, doi:10.1016/j.advwatres.2008.06.005, 2008.

Coe, M. T., Costa, M. H., and Howard, E. A.: Simulating the surface waters of the Amazon River basin: Impacts of new river geomorphic and flow parameterizations, Hydrol. Process., 22, 25422553, 2008.

Collischonn, W., Allasia, D. G., Silva, B. C., and Tucci, C. E. M.: The MGB-IPH model for large-scale rainfall-runoff modelling, Hydrolog. Sci. J., 52, 878-895, 2007.

Day, G. N.: Extended streamflow forecasting using NWSRFS, J. Water Resour. Plann. Manage., 111, 157-170, 1985.

Decharme, B., Alkama, R., Papa, F., Faroux, S., Douville, H., and Prigent, C.: Global off-line evaluation of the ISBA-TRIP flood model, Clim. Dynam., 38, 1389-1412, doi:10.1007/s00382-0111054-9, 2011.

Durand, M., Andreadis, K. M., Alsdorf, D. E., Lettenmaier, D. P., Moller, D., and Wilson, M.: Estimation of bathymetric depth and slope from data assimilation of swath altimetry into a hydrodynamic model, Geophys. Res. Lett., 35, L20401, doi:10.1029/2008GL034150, 2008.

Durand, M., Fu, L. L., Lettenmaier, D. P., Alsdorf, D. E., Rodríguez, E., and Fernandez, D. E.: The surface water and ocean topography mission: Observing terrestrial surface water and oceanic submesoscale eddies, Proc. IEEE, 98, 766-779, 2010a.

Durand, M., Rodríguez, E., Alsdorf, D., and Trigg, M.: Estimating River Depth From Remote Sensing Swath Interferometry Measurements of River, IEEE J. Sel. Top. Appl., 3, 20-31, 2010 b.

Espinoza, J. C., Ronchail, J., Guyot, J. L., Cocheneau, G., Filizola, N., Lavado, W., de Oliveira, E., Pombosa, R., and Vauchel, P.: Spatio-Temporal rainfall variability in the Amazon Basin Coun- tries (Brazil, Peru, Bolivia, Colombia and Ecuador), Int. J. Climatol., 29, 1574-1594, 2009.

Espinoza, J. C., Ronchail, J., Guyot, J. L., Junquas, C., Vauchel, P., Lavado, W., Drapeau, G., and Pombosa, R.: Climate variability and extreme drought in the upper Solimões River (western Amazon Basin): Understanding the exceptional 2010 drought, Geophys. Res. Lett., 38, L13406, doi:10.1029/2011GL047862, 2011.

Evensen, G.: The ensemble Kalman filter: theoretical formulation and practical implementation, Ocean Dynam., 53, 343-367, 2003.

Evensen, G.: Sampling strategies and square root analysis schemes for the EnKF, Ocean Dynam., 54, 539-560, 2004.

Evensen, G.: Data assimilation, The Ensemble Kalman Filter, 2nd Edn., Springer, 2009.

Farr, T. G., Caro, E., Crippen, R., Duren, R., Hensley, S., Kobrick, M., Paller, M., Rodriguez, E., Rosen, P., Roth, L., Seal, D., Shaffer, S., Shimada, J., Umland, J., Werner, M., Burbank, D., Oskin, M., and Alsdorf, D.: The shuttle radartopography mission, Rev. Geophys., 45, RG2004, doi:10.1029/2005RG000183, 2007.

Frappart, F., Ramillien, G., Maisongrande, P., and Bonnet, MP.: Denoising satellite gravity signals by Independent Component Analysis, IEEE Geosci. Remote Sens. Lett., 7, 421-425, doi:10.1109/LGRS.2009.2037837, 2010.

Frappart, F., Ramillien, G., Leblanc, M., Tweed, S. O., Bonnet, M.-P., and Maisongrande, P.: An Independent Component Analysis approach for filtering continental hydrology in the GRACE gravity data, Remote Sens. Environ., 115, 187-204, doi:10.1016/j.rse.2010.08.017, 2011.

Gedney, N., Cox, P. M., and Huntingford, C.: Climate feedback from wetland methane emission, Geophys. Res. Lett., 31, L20503, doi:10.1029/2004GL020919, 2004.

Getirana, A. C. V. and Peters-Lidard, C.: Estimating water discharge from large radar altimetry datasets, Hydrol. Earth Syst. Sci., 17, 923-933, doi:10.5194/hess-17-923-2013, 2013.

Getirana, A. C. V., Boone, A., Yamazaki, D., Decharme, B., Papa, F., and Mognard, N.: The Hydrological Modelling and Analysis Platform (HyMAP): evaluation in the Amazon basin, J. Hydrometeor, 13, 1641-1665, doi:10.1175/JHM-D-12-021.1, 2012.

Giustarini, L., Matgen, P., Hostache, R., Montanari, M., Plaza, D., Pauwels, V. R. N., De Lannoy, G. J. M., De Keyser, R., Pfister, L., Hoffmann, L., and Savenije, H. H. G.: Assimilating SARderived water level data into a hydraulic model: a case study, Hydrol. Earth Syst. Sci., 15, 2349-2365, doi:10.5194/hess-152349-2011, 2011.

Hess, L. L., Melack, J. M., Novo, E. M. L. M., Barbosa, C. C. F., and Gastil, M.: Dual-season mapping of wetland inundation and vegetation for the central Amazon basin, Remote Sens. Environ., 87, 404-428, 2003.

Hostache, R., Lai, X., Monnier, J., and Puech, C.: Assimilation of spatially distributed water levels into a shallow-water flood model. Part II: Use of a remote sensing image of Mosel River, J. Hydrol., 390 257-268, 2010.

Hostache, R., Matgen, P., Giustarini, L., Tailliez, C., and Iffly, J.F.: Tracking, sensing and predicting flood wave propagation using nomadic satellite communication systems and hydrodynamic models, Proc. SPIE 8174, Remote Sens. Agr. Ecosyst. Hydrol. XIII, 817407, doi:10.1117/12.897967, 2011. 
Huffman, G., Adler, R., Bolvin, D., Gu, G., Nelkin, E., Bowman, K., Hong, Y., Stocker, E., and Wolff, D.: The TRMM Multisatellite Precipitation Analysis (TCMA): quasi-global, multiyear, combined-sensor precipitation estimates at fine scales, J. Hydromet, 8, 38-55, 2007.

Kalman, R. E.: A new approach to linear filtering and prediction problems, Trans. AMSE - J. Basic Eng., 82 D, 35-45, 1960.

Krinner, G.: Impact of lakes and wetlands on boreal climate, J. Geophys. Res., 108, 4520, doi:10.1029/2002JD002597, 2003.

Kumar, S. V., Reichle, R. H., Peters-Lidard, C. D., Koster, R. D., Zhan, X., Crow, W. T., Eylander, J. B., and Houser, P. R.: A Land Surface Data Assimilation Framework using the Land Information System: Description and Applications, Adv. Water Resour., 31, 1419-1432, DOI:10.1016/j.advwatres.2008.01.013, 2008.

Lee, H., Seo, D.-J., and Koren, V.: Assimilation of streamflow and in situ soil moisture data into operational distributed hydrologic models: Effects of uncertainties in the data and initial model soil moisture states, Adv. Water Resour., 34, 1597-1615, doi:10.1016/j.advwatres.2011.08.012, 2011.

Lee, H., Seo, D.-J., Liu, Y., Koren, V., McKee, P., and Corby, R.: Variational assimilation of streamflow into operational distributed hydrologic models: effect of spatiotemporal scale of adjustment, Hydrol. Earth Syst. Sci., 16, 2233-2251, doi:10.5194/hess-16-2233-2012, 2012.

Leon, J. G., Calmant, S., Seyler, F., Bonnet, M.-P., Cauhopé, M., and Frappart, F.: Rating curves and average water depth at the Upper Negro river from satellite altimetry and modelled discharges, J. Hydrol., 328, 481-496, 2006.

Liu, Y. and Gupta, H. V.: Uncertainty in hydrologic modelling: Toward an integrated data assimilation framework, Water Resour. Res., 43, W07401, doi:10.1029/2006WR005756, 2007.

Liu, Y., Weerts, A. H., Clark, M., Hendricks Franssen, H.-J., Kumar, S., Moradkhani, H., Seo, D.-J., Schwanenberg, D., Smith, P., van Dijk, A. I. J. M., van Velzen, N., He, M., Lee, H., Noh, S. J., Rakovec, O., and Restrepo, P.: Advancing data assimilation in operational hydrologic forecasting: progresses, challenges, and emerging opportunities, Hydrol. Earth Syst. Sci., 16, 3863-3887, doi:10.5194/hess-16-3863-2012, 2012.

Marengo, J., Nobre, C., Tomasella, J., Oyama, M., de Oliveira, G., de Oliveira, R., Camargo, H., and Alves, L.: The drought in Amazonia in 2005, J. Climate, 21, 495-516, 2008.

Marengo, J. A., Tomasella, J., Alves, L. M., Soares, W. R., and Rodriguez, D. A.: The drought of 2010 in the context of historical droughts in the Amazon region, Geophys. Res. Lett., 38, L12703, doi:10.1029/2011GL047436, 2011.

Matgen, P., Montanari, M., Hostache, R., Pfister, L., Hoffmann, L., Plaza, D., Pauwels, V. R. N., De Lannoy, G. J. M., De Keyser, R., and Savenije, H. H. G.: Towards the sequential assimilation of SAR-derived water stages into hydraulic models using the Particle Filter: proof of concept, Hydrol. Earth Syst. Sci., 14, 17731785, doi:10.5194/hess-14-1773-2010, 2010.

McMillan, H. K., Hreinsson, E. Ö., Clark, M. P., Singh, S. K., Zammit, C., and Uddstrom, M. J.: Operational hydrological data assimilation with the recursive ensemble Kalman filter, Hydrol. Earth Syst. Sci., 17, 21-38, doi:10.5194/hess-17-21-2013, 2013.

Meade, R. H., Rayol, J. M., Da Conceição, S. C., and Natividade, J. R. G.: Backwater effects in the Amazon River basin of Brazil, Environ. Geol. Water Sci., 18, 105-114, 1991.
Melack, J. M. and Hess, L. L.: Remote sensing of the distribution and extent of wetlands in the Amazon basin, in: Amazonian floodplain forests: ecophysiology, ecology, biodiversity and sustainable management, edited by: Junk, W. J. and Piedade, M., Ecological Studies, Vol. 210, Part 1, Springer, 43-59, 2010.

Neal, J. C., Atkinson, P. M., and Hutton, C. W.: Flood inundation model updating using ensemble Kalman filter and spatially distributed measurements, J. Hydrol., 336, 401-415, 2007.

Neal, J. C., Schumann, G. J.-P., Bates, P. D., Buytaert, W., Matgen, P., and Pappenberger, F.: A data assimilation approach to discharge estimation from space, Hydrol. Process., 23, 3641-3649, doi:10.1002/hyp.7518, 2009.

New, M., Lister, D., Hulme, M., and Makin, I.: A high-resolution data set of surface climate over global land areas, Clim. Res., 21, 1-25, 2002.

Nijssen, B. and Lettenmaier, D.: Effect of precipitation sampling error on simulated hydrological fluxes and states: Anticipating the Global Precipitation Measurement satellites, J. Geophys. Res., 109, D02103, doi:10.1029/2003JD003497, 2004.

Oki, T. and Kanae, S.: Global hydrological cycles and world water resources, Science, 313, 1068-1072, doi:10.1126/science.1128845, 2006.

Paiva, R. C. D., Collischonn, W., and Tucci, C. E. M.: Large scale hydrologic and hydrodynamic modelling using limited data and a GIS based approach, J. Hydrol., 406, 170-181, 2011.

Paiva, R. C. D., Collischonn, W., Bonnet, M. P., and de Gonçalves, L. G. G.: On the sources of hydrological prediction uncertainty in the Amazon, Hydrol. Earth Syst. Sci., 16, 3127-3137, doi:10.5194/hess-16-3127-2012, 2012.

Paiva, R. C. D., Collischonn, W., and Buarque, D. C.: Validation of a full hydrodynamic model for large scale hydrologic modelling in the Amazon, Hydrol. Process., 27 333-346, doi:10.1002/hyp.8425, 2013a.

Paiva, R. C. D., Collischonn, W., Bonnet, M.-P., Buarque, D. C., Frappart, F., Calmant, S., and Mendes, C. B.: Large scale hydrologic and hydrodynamic modelling of the Amazon River basin, Water Resour. Res., 49, 1226-1243, doi:10.1002/wrcr.20067, $2013 b$.

Papa, F., Durand, F., Rossow, W. B., Rahman, A., and Bala, S. K.: Satellite altimeter-derived monthly discharge of the Ganga-Brahmapoutra River and its seasonal to interannual variations from 1993 to 2008, J. Geophys. Res., 115, C12013, doi:10.1029/2009JC006075, 2010a.

Papa, F., Prigent, C., Aires, F., Jimenez, C., Rossow, W. B., and Matthews, E.: Interannual variability of surface water extent at the global scale, 1993-2004, J. Geophys. Res., 115, D12111, doi:10.1029/2009JD012674, 2010b.

Pereira-Cardenal, S. J., Riegels, N. D., Berry, P. A. M., Smith, R. G., Yakovlev, A., Siegfried, T. U., and Bauer-Gottwein, P.: Real-time remote sensing driven river basin modelling using radar altimetry, Hydrol. Earth Syst. Sci., 15, 241-254, doi:10.5194/hess-15241-2011, 2011.

Rakovec, O., Weerts, A. H., Hazenberg, P., Torfs, P. J. J. F., and Uijlenhoet, R.: State updating of a distributed hydrological model with Ensemble Kalman Filtering: effects of updating frequency and observation network density on forecast accuracy, Hydrol. Earth Syst. Sci., 16, 3435-3449, doi:10.5194/hess-163435-2012, 2012. 
Reichle, R. H.: Data assimilation methods in the Earth sciences, Adv. Water Resour., 31, 1411-1418, doi:10.1016/j.advwatres.2008.01.001, 2008.

Reichle, R. H., Mclaughlin, D. B., and Entekhabi, D.: Hydrologic Data Assimilation with Ensemble Kalman Filter, Mon. Weather Rev., 130, 103-114, 2002.

Ricci, S., Piacentini, A., Thual, O., Le Pape, E., and Jonville, G.: Correction of upstream flow and hydraulic state with data assimilation in the context of flood forecasting, Hydrol. Earth Syst. Sci., 15, 3555-3575, doi:10.5194/hess-15-3555-2011, 2011.

Rozante, J. R., Moreira, D. S., de Goncalves, L. G. G., and Vila, D .A.: Combining TRMM and Surface Observations of Precipitation: Technique and Validation over South America, Weather Forecast., 25, 885-894, doi:http://dx.doi.org/10.1175/2010WAF2222325.1, 2010.

Sakov, P. and Bertino, L.: Relation between two common localisation methods for the EnKF, Comput. Geosci., 15, 225-237, doi:10.1007/s10596-010-9202-6, 2010.

Santos da Silva, J., Calmant, S., Seyler, F., Rotunno Filho, O. C., Cochonneau, G., and Mansur, W. J.: Water levels in the Amazon basin derived from the ERS 2 and ENVISAT radar altimetry missions, Remote Sens. Environ., 114, 2160-2181, 2010.

Thielen, J., Bartholmes, J., Ramos, M.-H., and de Roo, A.: The European Flood Alert System - Part 1: Concept and development, Hydrol. Earth Syst. Sci., 13, 125-140, doi:10.5194/hess-13-1252009, 2009.

Thirel, G., Martin, E., Mahfouf, J.-F., Massart, S., Ricci, S., and Habets, F.: A past discharges assimilation system for ensemble streamflow forecasts over France - Part 1: Description and validation of the assimilation system, Hydrol. Earth Syst. Sci., 14, 1623-1637, doi:10.5194/hess-14-1623-2010, 2010.

Tian, Y. and Peters-Lidard, C. D.: A global map of uncertainties in satellite-based precipitation measurements, Geophys. Res. Lett., 37, L24407, doi:10.1029/2010GL046008, 2010.
Tomasella, J., Borma, L. S., Marengo, J. A., Rodriguez, D. A., Cuartas, L. A., Nobre, C. A., and Prado, M. C. R.: The droughts of 1996-1997 and 2004-2005 in Amazonia: hydrological response in the river main-stem, Hydrol. Process., 25, 1228-1242, doi:10.1002/hyp.7889, 2010.

Trigg, M. A., Wilson, M. D., Bates, P. D., Horritt, M. S., Alsdorf, D. E., Forsberg, B. R., and Vega, M. C.: Amazon flood wave hydraulics, J. Hydrol., 374, 92-105, 2009.

Uvo, C. B. and Graham, N. E.: Seasonal runoff forecast for northern South America: A statistical model, Water Resour. Res., 34, 3515-3524, doi:10.1029/98WR02854, 1998.

Uvo, C. B., Tölle, U., and Berndtsson, R.: Forecasting discharge in Amazonia using artificial neural networks, Int. J. Climatol., 20, 1495-1507, doi:10.1002/1097-0088(200010)20:12<1495::AIDJOC549>3.0.CO;2-F, 2000.

Vrugt, J. A., Diks, C. G. H., Gupta, H. V., Bouten, W., and Verstraten, J. M.: Improved treatment of uncertainty in hydrologic modelling: Combining the strengths of global optimization and data assimilation, Water Resour. Res., 41, W01017, doi:10.1029/2004WR003059, 2005.

Wilks, D. S.: Statistical Methods in the Atmospheric Sciences, 2st Edn. Academic Press, 627 pp., 2006.

Wilson, W., Bates, P., Alsdorf, D., Forsberg, B., Horritt, M., Melack, J., Frappart, F., and Famiglietti, J.: Modelling large-scale inundation of Amazonian seasonally flooded wetlands, Geophys. Res. Lett., 34, L15404, doi:10.1029/2007GL030156, 2007.

Wood, A. W., Maurer, E., Kumar, A., and Lettenmaier, D. P.: Longrange experimental hydrologic forecasting for the eastern United States, J. Geophys. Res., 107, 4429, doi:10.1029/2001JD000659, 2002.

Yamazaki, D., Kanae, S., Kim, H., and Oki, T.: A physically n dynamics in a global river routing model, Water Resour. Res., 47, W04501, doi:10.1029/2010WR009726, 2011. 